\title{
A Disaster Management Framework Using Internet of Things-Based Interconnected Devices
}

\author{
Kaljot Sharma, ${ }^{1}$ Darpan Anand, ${ }^{1}$ Munish Sabharwal, ${ }^{2}$ Pradeep Kumar Tiwari $\left(\mathbb{D},{ }^{3}\right.$ \\ Omar Cheikhrouhou $\mathbb{D}^{4},{ }^{4}$ and Tarek Frikha $\mathbb{D}^{5}$
}

${ }^{1}$ Department of CSE, Chandigarh University, Ajitgarh, Punjab, India

${ }^{2}$ Galgotias University, Noida, India

${ }^{3}$ Manipal University Jaipur, Jaipur, India

${ }^{4}$ College of Computers and Information Technology, Taif University, P.O. Box 11099, Taif 21944, Saudi Arabia

${ }^{5}$ Sfax University, National Engineering School of Sfax, CES Lab, Sfax, Tunisia

Correspondence should be addressed to Tarek Frikha; tarek.frikha@enis.tn

Received 14 March 2021; Revised 21 April 2021; Accepted 30 April 2021; Published 20 May 2021

Academic Editor: Kehui Sun

Copyright (c) 2021 Kaljot Sharma et al. This is an open access article distributed under the Creative Commons Attribution License, which permits unrestricted use, distribution, and reproduction in any medium, provided the original work is properly cited.

\begin{abstract}
The advanced technology Internet of Things (IoT) visualizes a worldwide, that is, internally connected, networks of smart physical entities. IoT is a promising technology used in several applications including disaster management. In disaster management, the role of IoT is so important and ubiquitous and could be life-saving. This article describes the role of IoT in disaster management. More precisely, it presents IoT-based disaster management for different kind of disasters with a comparison between some solutions that are available in the market. It shows an implementation of some examples of the application of IoT such as earlywarning system for fire detection and earthquake and represents some approaches talking about the application, IoT architecture, and focusing of the study on different disasters. This study could be a good guide to stakeholder about the use of IoT technology to secure their smart cities' infrastructure and to manage disaster and reduce risks.
\end{abstract}

\section{Introduction}

Internet has emerged and become the new telecommunication brand platform which is fully developed. The major accomplishment over several years is a new protocol (VoIP) voice over Internet protocol. Due to Internet development, the IoT technology emerges. For getting control over the devices, there's a method of IoT that associates existing resources to the Internet. The Massachusetts Institute of Technology (MIT) Auto Labs became the first to implement the idea of IoT in the early 1990's. Also, the first IoT application was the trojan area coffee pot which is developed in 1999 [1]. The toaster is the world's initially measuring device of the Internet that could be turned off or on according to ones will, and it was later developed throughout the constant years. Many of the organizations are working on the main domain of IoT, and there are many kinds of definitions proposed over the years [2].
Due to the advancement in technology, the definitions of IoT are gaining new insights by organizations. From those organizations, one termed this definition, "global structure for data society, enabling progressive services by bury connecting (physical and virtual) belongings based on existing and evolving, interrogatable data, and communication technologies." The IoT allows the synchronization. In the building of this concept, human intervention makes it possible. As time passed, there are constant changes in technologies and advancements in the field of the Internet. The 2nd phase Internet of Content was introduced, and giant messages can be sent. In the 3rd phase Internet of service, the email facility was provided and associated with attachments and data and recreation of these were the most utilized prospects of this phase. This advanced IoT time has the potential to attach devices across the globe. That is why all these devices will connect and communicate with each other and perform different activities as shown by programmed 
steps with a style of objects which is different. For the concept of this era, it was not the end of the road. However, the ideas of computer science are included by the researchers upon those devices which are connected without the intervention of human beings. As we might say, computer science is driven by the Internet of Things. As shown in Figure 1, there is a transition of the Internet from the preInternet. The Internet of Things has been the fourth revolution of Business 4.0. The main objective of Industry 4.0 IoT is always to earn maximum profits through the use of interconnected machines and intelligent objects and to increase the efficiency of Internet-connected production. Deploying different IoT devices such as sensors, cloud-based solutions, and edge computing for the manufacturing and transformation units increased the productivity of the organizations. The divided parts of the production's units must work according to the standards of heterogeneous producing IT landscapes. By the usage of IoT, the enterprises are extended seamlessly and are very visible, and the opportunity of new business is the result of it, which was unimagined in previous time.

In this article, we describe the important role of IoT in the field of the management of disaster. More precisely, it presents IoT-based disaster management for different kind of disasters with a comparison between some solutions that are available in the market.

The reminder of this paper is as follows. Section 2 explains the evolution of the Internet of Things. Section 3 provides information about the disaster management phases with some light on reports of disasters according to the EDdata database and classification of the disasters. Section 4 presents the traditional methods used for early warnings in disasters. Section 5 presents IoT-based disaster management of different disasters with the comparison between some solutions for disasters which are available in the market. Section 6 shows an implementation of some examples of the application of IoT such as early-warning system for fire detection and earthquake and describes approaches that talk about the application, IoT architecture, and focus of the study of different disasters. Section 7 presents other applications of IoT such as home automation and healthcare. Section 8 briefly talks about the future challenges and draws some conclusions.

1.1. Evolution of Internet of Things. In terms of communication evolution of the Internet, IoT has become the benchmark. Over billions of devices, this language in today's state has taken management by using sensors supporting their working efficiency. By connecting these sensor devices which generate a huge amount of information that was processed for further cognitive knowledge, there has been a sharp inclination of usage or adaption of new technologies since the past few years. The latest age communications are used through past years. Till now five billion devices are connected or deployed.

It has already been reported that around 50 billion users will be interconnected to each other through that Internet by the year $2020[3,4]$. The latest modes of obtaining the new systems are sensors that enhance the vision of the case of New Networking Technology over the Internet [5]. If we want to specifically measure the utility of the Internet of Things capabilities, it would be very foolish, but even knowing it, developments in the Internet of Things sector from time to time will change and the Internet of Things field will advance. In the past few years, there has been an increase of the devices which are connected over the Internet. With a facility of further sensors, the outcomes depict the continuing increase of devices and finding new methodologies which are associated with various devices over the Internet of Things. IoT devices have been of great importance for this development roadmap for several areas, for example, a good quality, good homes or buildings, and smart grid; many more applications such as public safety and agriculture and reproduction are a few of the surrounding findings or manufacturing methods for medical and healthcare.

\section{Literature Survey}

\subsection{Background of IOT-Enabled Disaster Management} System. The background of IoT-enabled disaster management systems starts with the IoT. The Arpanet-linked coke device was built by four students at Carnegie Mellon to tell if the Coca-Cola in the cane was hot or cold in 1982. The main idea to estimate was that how many bottles of Coke were left in that line and even how long this would have lasted. If it is left on the system line for such a long period, it is called "chilled." By using the fingerprint interface, this entire machine will serve customers. This experiment encourages many researchers and scientists to create connected appliances for the world [6]. At the beginning of the 1990s, IBM scientists proposed and patented Ultra-High Frequency (UHF) and Rfid Tags (RFID), which covered a wider distance and permitted faster data transmission. In the mid1990s, IBM conducted many pilot experiments, but with the issues that make them auction their patents to the Intermec barcode technology, they will never start marketing this revolutionary invention. Intermec RFID systems are implementing many implementations of such an innovation, and due to the cost of technology at the time and limited power, it has not been distributed as anticipated by Intermac. For this incident, Professor David Brock and Sanjay Sharma suggested RFID tags to track the different items in the distribution chain in which they decided to use the very bar code tags to monitor the items to save the price of the service and to manufacture more complex shapes with bigger, more costly memory capacity. The FID tags associated with the data link have been placed in the database and accessible via the Internet [7]. A few research and journals have reported that Ashton, Executive Director, in MIT ID Centre in 1999, first launched the Internet of Things $[8,9]$. Aston suggests that the Internet of Things has the potential to change the environment as often as the Internet has done and more [6]. However, some of the studies claimed that Neil Gerstenfeld's area was also the one who first talked about the concept of the IoT and the title of the book 'When Things Start to Think' [10]. Table 1 explains the production stages of the IoT systems from 1982 to 2021. 


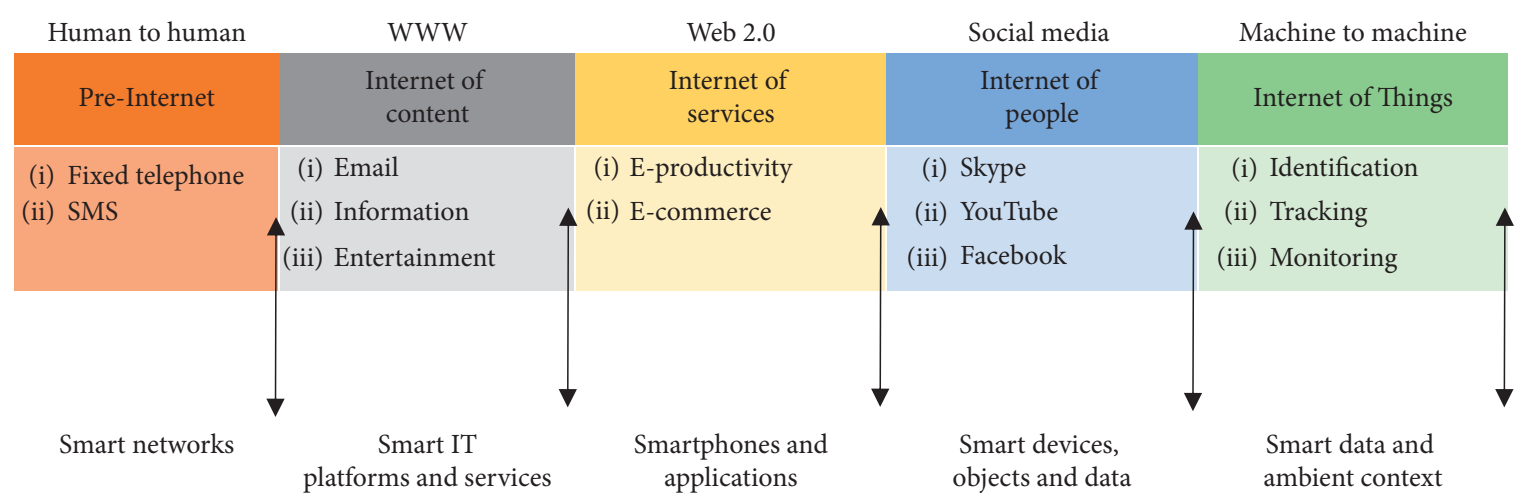

FIgURE 1: Evolution from pre-Internet to Internet of things.

TABle 1: IoT framework stages from 1982 to 2021.

\begin{tabular}{|c|c|}
\hline \multicolumn{2}{|r|}{ Overview of the production phases of IoT spanning from 1982 to 2021} \\
\hline 1982 & From Carnegie Mellon University, four students have developed the ARPAnet-connected coke unit \\
\hline 1989 & Sir Tim has introduc \\
\hline 1990 & John Romkey has launched a toaster attached to Internet \\
\hline 1999 & Neil Gerstenfeld wrote about the basis of IoT in his book "When Things Start to think" \\
\hline 1999 & For the first time, Kevin Ashton presented the idea of the "Internet of Things" \\
\hline 2000 & LG has revealed the first Internet-enabled fridge the world has ever known \\
\hline 2004 & The idea of IoT became more popular, and there have been ma \\
\hline 2005 & $\begin{array}{l}\text { Nabaztag Internet-connected gadgets have emerged, which were a low-price robot, designed to link to Wi-Fi networks to collect } \\
\text { weather reports and news, share price shifts, and be read by the user }\end{array}$ \\
\hline 2008 & In Zurich, Switzerland, the first international conference of IoT was held \\
\hline 2009 & $\begin{array}{r}\text { Google has begun testing self-driving vel } \\
\text { pedestri }\end{array}$ \\
\hline 2010 & China was selecting IoT as a main industry; Chinese $\operatorname{Pr}$ \\
\hline 2011 & IPv6 public rolled out many organizations which have urged Intern \\
\hline 2013 & Google unveiled smart glasses, displayed with the ability to pres \\
\hline 2015 & $\begin{array}{c}\text { They created a Barbie with built-in Wi-Fi module and a toy house including interactive features such as a voice activated light and a } \\
\text { toy oven with fireplace }\end{array}$ \\
\hline & Apple launched home appliances package to provide \\
\hline & area \\
\hline 2017 & $\begin{array}{c}\text { Microsoft introduced the Azure IoT edge that allows small appliances to use cloud services even though they are not wired to the } \\
\text { cloud }\end{array}$ \\
\hline 2018 & Government has begun to think about the safety of IoT devices and to $u$ \\
\hline 201 & \\
\hline 2021 & BMW, Ford, and Volvo say that they are going to get fully autonomous vehicles \\
\hline
\end{tabular}

\section{Analysis of Classification of Disaster Management}

3.1. What Is Disaster? WHO describes disaster as " any event that causes disruption to the environment, loss of human life, and loss of health services. It requires an extraordinary intervention from anywhere in the affected community or area." While the concept of disasters can vary from one expert to another, a catastrophe may define many public health professionals as being a sudden, extraordinary disaster, which affects or threatens health [11]. In general, a disaster is a natural or man-made hazard, resulting in significant physical harm, loss of life, and damage. Disaster may ostensibly be described as any disastrous incident arising from disasters such as hurricanes, flooding, catastrophic incidents, fire, or blast. It is a practice in which disasters can ruin people's lives, property, and economic, cultural, and social lives. Disaster can have features such as speed, urgency, confusion, unpredictability, hazard, and loss of human life, animal life, and property [11]. There are various policies for emergency recovery that are intended to minimize the effects of a disaster, and we cannot cure it but certainly mitigate the impact. Any floods can be avoided by early-warning systems, but we cannot heal them in the event of drought. So, there are policies that can help to prevent it from occurring.

3.2. Disaster Prevention Policy. Preparedness: predisaster practices, for example, preparedness plans, emergency exercise/training, and alert systems. Response: crisis operations, for example, public alert devices, emergency isolation, and search. Rescue recovery: disaster-based practices such as transitional shelter, claims' collection and grants, long-term 
medical treatment, and therapy. Mitigation: disaster-effective activities such as building code and zoning, public education, and vulnerability. Figure 2 illustrates phases of disaster management.

It has been estimated that 217 million people were affected annually by natural calamities between 1994 and 2013 [12]. It has also been recorded that between 2000 and 2011 , a total of $\$ 15.3$ billion in damage and million new cases of cancer were related to the incidence of natural disasters. This culminated in "over 65 million immigrants and refugees fleeing worldwide" [13] in 2016. In 2016, the UN held, again for the first period from its 70 -year existence, a global conference on disaster relief and said that "today human suffering is greater than ever before time since the Second World War." Approximately, 133 million people worldwide are estimated to be dependent on foreign aid to survive [14]. This has led to a renewed emphasis on emergency recovery policy, which has the potential to drastically alleviate the suffering of people around the world [15]. Therefore, many international improvements were achieved as well as rewards for effective management have been recognized [16]. Environmental events also influence society in the developing world; however, developed nations get the potential to accept preventing effective intervention rather than postevent firefighting. This is a much more successful approach to dealing with environmental hazards through the introduction of regulatory processes, creating contingency plans and proposals to mitigate the likelihood of potential disasters. The International Association for Emergency Management (IAEM) is a nonprofit specialist organization committed to promoting the goals of saving lives and preserving facilities in the event of emergencies and disasters. The goal of the IAEM is to assist its members through the provision of information, networking and educational opportunities, and development of the emergency management profession. There are seven councils all over the world, Asia, Canada, Europe, the Nations, Oceania, Students, and the United States, and the EU has adopted the Community Civil Protection System, which has begun to play an important role at a national scale. The primary function of the system is to promote coordination in civil protection aid measures in the case of global crises which may need immediate action. This also extends to circumstances when there might be an immediate danger to certain major emergencies. The monitoring and knowledge centre is at the core of the mechanism. It is the representative including its Chairman for Humanitarian Aid and Civil Protection of the EU Parliament and is open 24/7 a day. It allows countries to link to a platform, only one civil defense agency, which is available to all the nations concerned. Any country, either in or out of the Union that has been hit by either a major tragedy, could call for assistance over the MIC. It acts just as a coordination point among involved nations, the country concerned, and field experts at the appropriate time. It also includes useful and up-to-date information regarding the present status of the ongoing incident. The International Recovery Platform (IRP) was launched at the World Summit Reduction (WCDR) in

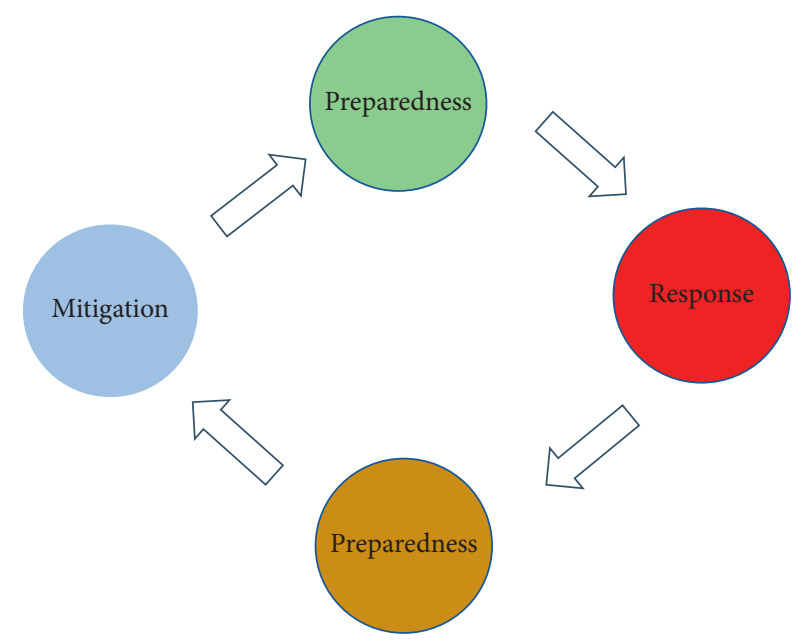

FIgURE 2: Phases of disaster management.

Lonzo, Louis, Japan, in mid-January 2005. As the textual platform for the International Relations for Disaster Mitigation (ISDR) framework, the IRP seems to be the central pillar for the adoption of the Hyogo Mechanism for Practice (HFA), 2005-2015; improving the stability of nations and communities to crises, a major catastrophe risk mitigation policy is embraced by 160 policymakers in the WCDR and for a decade. The key role of the IRP is to identify the deficiencies and restrictions encountered in postdisaster restoration and to act as a forum for the development of infrastructure, facilities, and comprehensive recovery capability. The IRP strives to be an international source of information on successful rehabilitation practices [11]. There are some of the multinational steps that the governments of all countries around the world are taking. However, this is also not satisfactory to reduce the repulsion of the catastrophe, and there is a need for technology that can help to heal faster and attempt to find the disaster before it occurs. Figures 3-6, collected from EDDAT, a national database of natural and technological threats, contain key details on the occurrence and effect of more than 21,000 disaster events from 1900 to the current. EM-DAT is maintained by the Centre for Crisis Epidemiology Research (CRED) at the School of Public Health of the Nerds chrétienne de Louvain, Berlin, Bavaria. The main priorities are to facilitate humanitarian action at the federal and state level; streamlining the assessment of emergency preparedness would provide an empirical context for risk assessment and priority management.

Additionally, the studies in [17] facilitated the researcher in overall preparation of literature review and planning for the overall research and assisted in analysis.

3.3. Classifications of Disasters. EM-DAT distinguishes two primary classes of disasters: natural disasters and technical disasters. This area is immediately related to the catastrophe subgroup and the form of disaster.

In Table 2, there is a general classification of various disasters. 


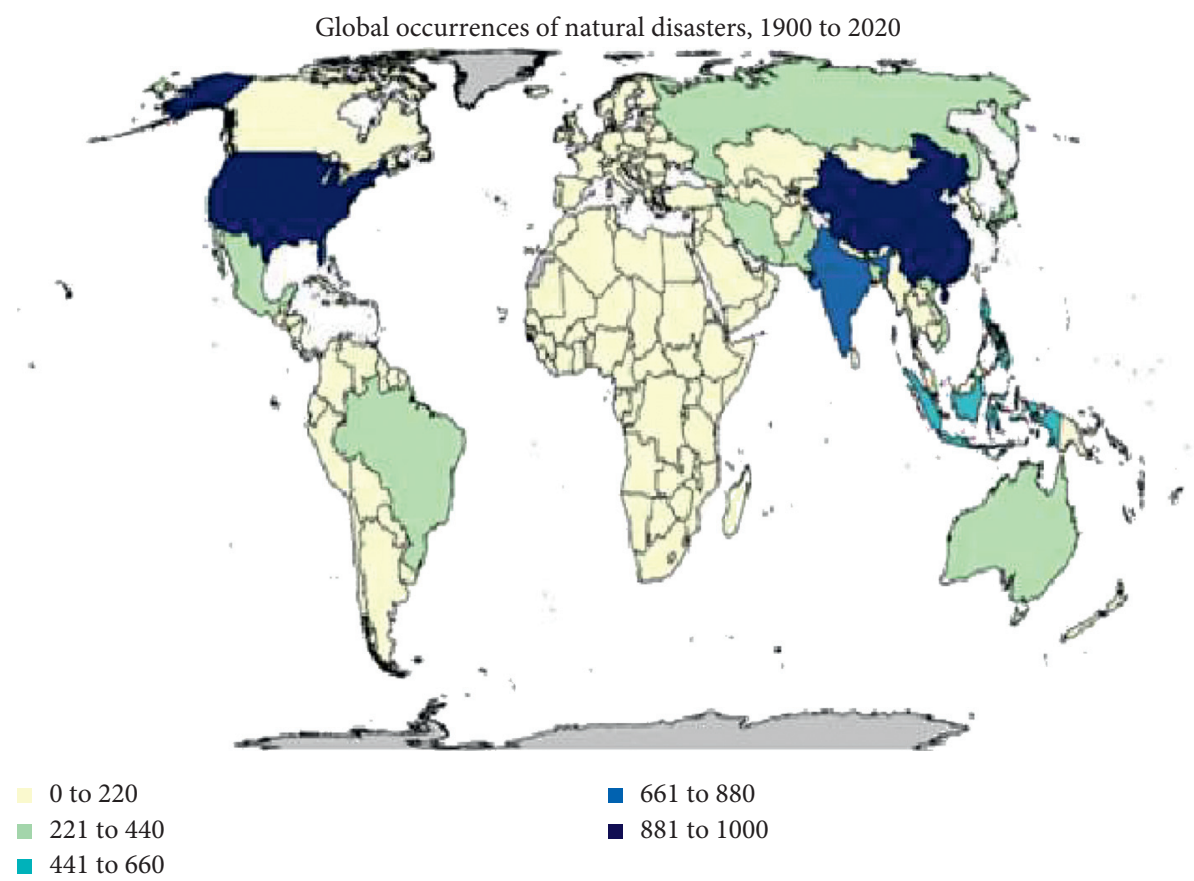

FIgURE 3: The ED-DAT database of disasters shows the impact of natural disaster in the world between 1900 and 2020.

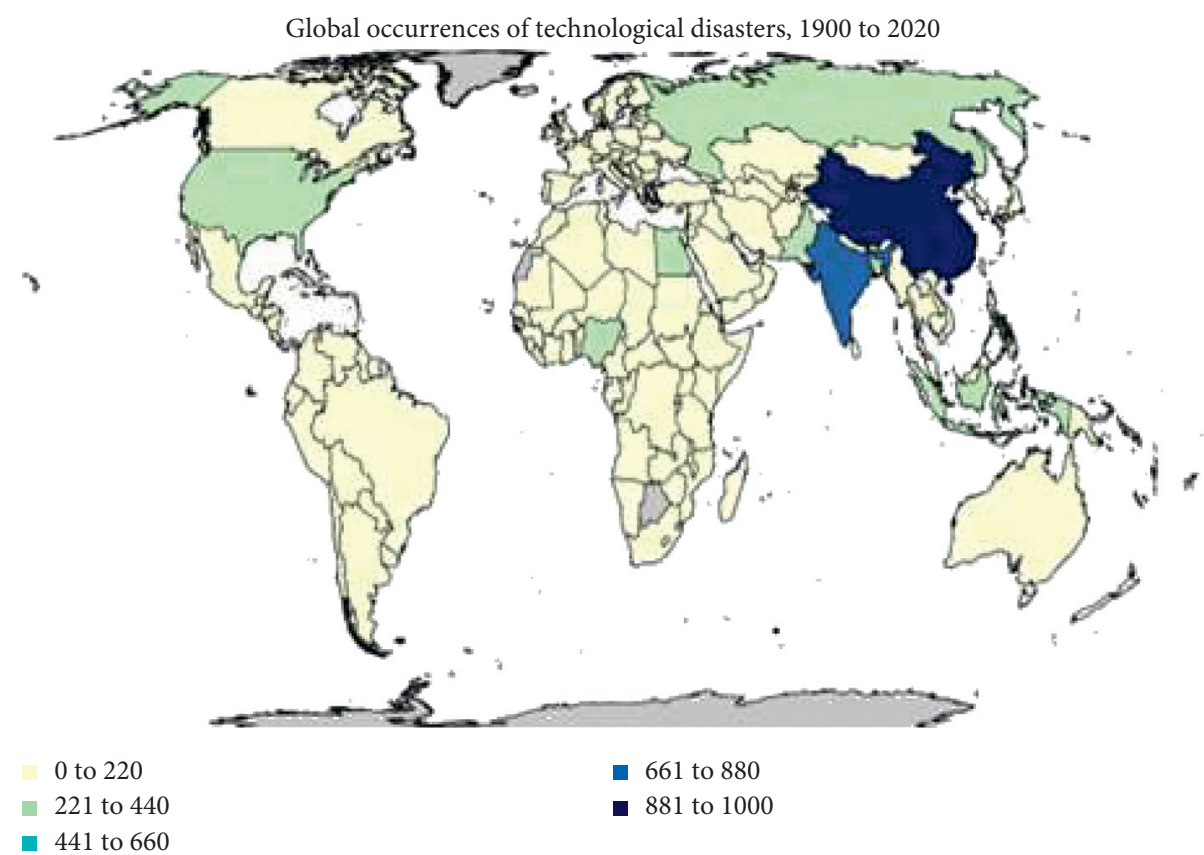

FIgURE 4: The ED-DAT database of disasters shows how countries are affected by technological disaster in the world between 1900 and 2020.

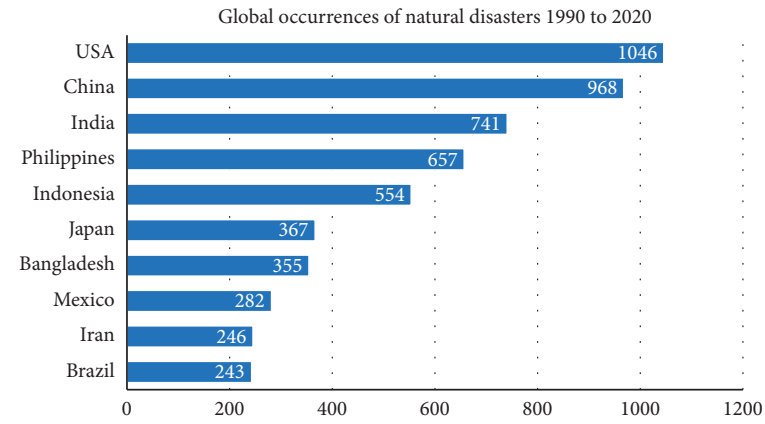

Figure 5: Top 10 natural disaster-affected countries reported. 


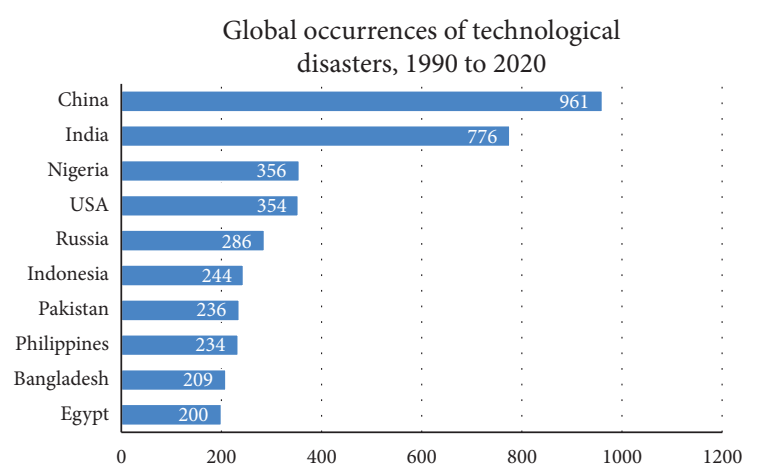

Figure 6: Top 10 technological disaster-affected countries reported.

\section{Part of DM}

\subsection{Traditional Early Warning Systems}

4.1.1. Radio and TV. Radio and television stay the conventional media used in crisis relief, since they are comparatively inexpensive, offer a secure yet another form of communication, and, perhaps importantly, do not involve literacy. Radio is the much more open channel for the vulnerable, particularly women in rural households, sailors at sea, or employees in the sector. Broadcast TV, although more effective, is more costly or otherwise not usable. It is not shocking, then, that radio is the way to connect for emerging threats in Karachi, Pakistan. The densely populated coastal city of Karachi faces many forms of hazards-explosions, tornadoes, and flooding-but has EWS just for typhoons and rising seas. With such a good degree of illiteracy and even a low rate of telephony, radio probably is the most used, mostly publicly available, and most powerful medium, while television is claimed to be gaining ground. However, still, rechargeable battery radio is a privilege in the poorest areas. The Foreplay Lifesaver radio was developed especially for these situations. It has stable connections to AM, FM, and shortwave channels and both weather and battery storage; it can survive dirt, liquid, and hot humidity. The Mozambican Red Cross incorporated the Lifeline Foreplay radio through its typhoon and flooded earlywarning operations. A volunteer has been indicated mostly by listening to the radio. Whenever an alarm is noticed, the coordinator warns village officials, and a preplanned action is started. This has already been attributed to a drastic decline in tornados and flood destruction. There were 800 deaths in the 2000 floods, 20 in 2006, and none in 2008. This form of radio was also used in the planning of hurricanes in Cuba as well as in RANET ventures in Togo, Ethiopia, and Nigeria. Radio and television, furthermore, are constrained by the fact that they sometimes have one-way contact and are usually shut off at night.

4.1.2. Satellite Radio. Satellite radio derives its signal from a communication satellite and does have a wider domain than commercial radio. It is very handy when the transmission towers get affected. Satellite radio, paired with portable or cell phones, has been found to become the most powerful and accurate of five ICT resources out of seven which depend on two factors to relay emergency alert support from government entities to 64 at-risk villagers in Bangladesh. This configurable satellite radios for emergency alerting (AREA) network is being paired with GPS to deliver threat alerts in textual and audio content directly with individual at-risk communities in the country, Malaysia, Singapore, and Taiwan. Satellite use, however, is very expensive for both the facilities set up and the purchase of geostationary radio, and the coverage can be disrupted by trees, walls, and other environmental conditions.

4.1.3. Telephones (Fixed and Mobile). A single-to-one emergency warning is helpable for telephones (fixed and mobile). Telephone trees in certain nations are being used to speed up their spread of notifications. This same major downside is that they are a one-to-one communication medium, in which lines could be overcrowded before or during a catastrophe and telephone access remains a privilege in several regions, even though several rural people with low fixed telephone stimulation are increasingly using cellular modems. In the Giang and Jin Thap territories of Vietnam, which were set up following the severe August 2008 Mekong floods, cell devices were the main approach to implement population flooding monitoring and emergency plan. Twenty at-risk cities and towns were provided with cell devices, and residents in seven villages were equipped to evaluate water levels twice a day during monsoon season. They alert Nanjing City, the central regulatory body for flood forecasts, of their water level readings through texts and emails to the Southern Area Hydro-Meteorological Unit. The Council's computers hold the details, and the measured flood prediction is mirrored in the residents who release data on bulletin boards mostly in the region. The publication of any immediate threat to floods is carried out through huge speakers. Mobile telecommunications companies were likewise supportive when Tornado Iman arrived in Hawaii in 2004. The same day before a storm struck the nearby island of Granada, Fijian Red Cross workers and parish emergency panel officials used mobile phones to make a warning. Shortto-many text-based emergency warnings are an additional instrument that can be supported in most cell devices with Short Message Service (SMS). The sensor monitoring for building authenticity (about typhoons) is being used in Beijing. It is indeed one including EWS. Before a cyclone is struck, evacuation warnings via SMS are forwarded to people. The use of SMS is restricted to traffic and could be given just to preregister and educate users.

4.1.4. Cell Broadcasting. Cell transmission is a geographic SMS service that targets one-to-many operations. It is now embedded into most current network services and infrastructure, so line laying and buying new applications or new modems do not require extra costs. It requires a standard channel which thus does not impact the load distribution nor contribute to the local broadcast capacity. The transmission can be geo-scaled such that a message hits million 
TABLE 2: General classification of various disasters.

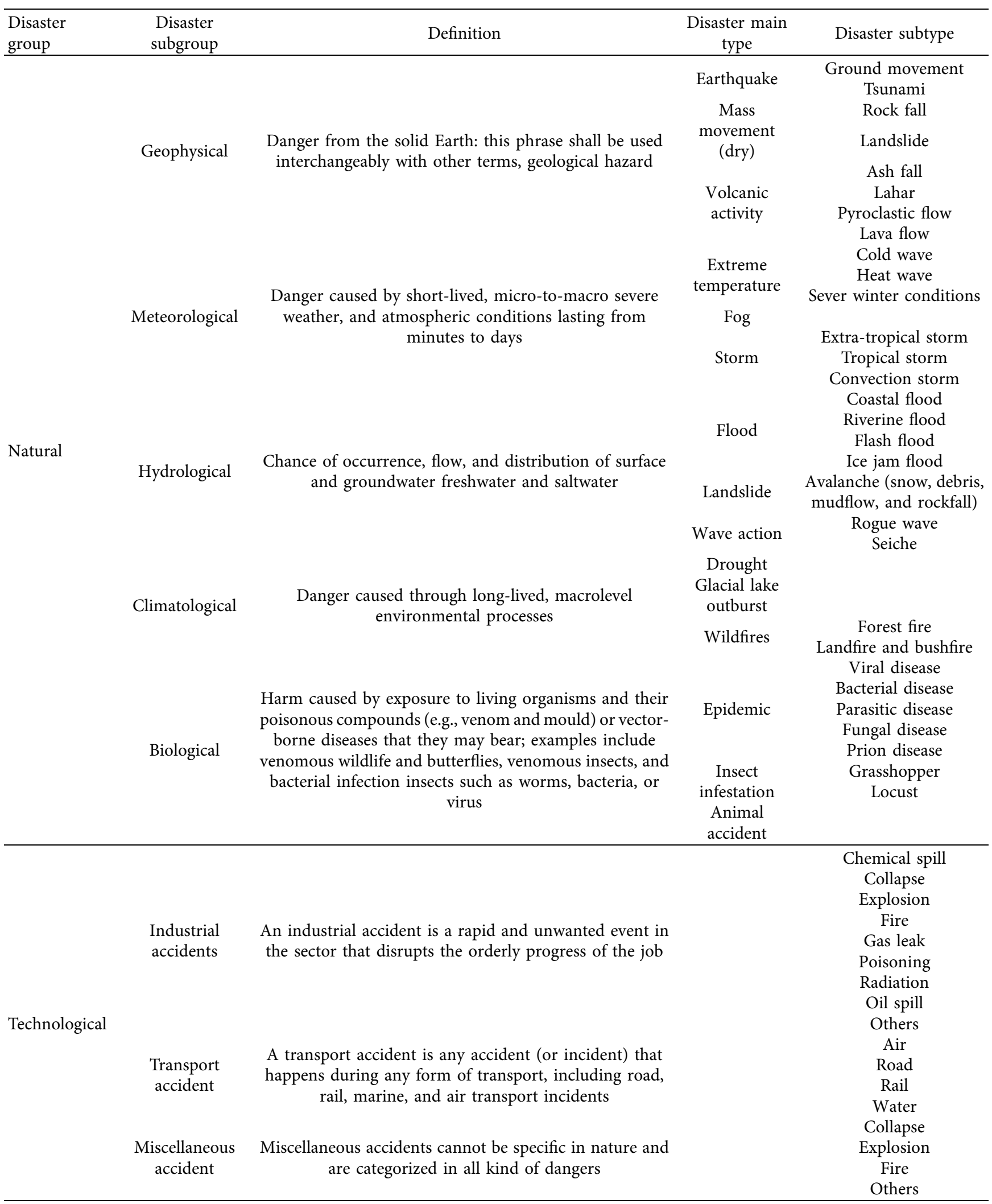

with one moment; it is geo-specific, thereby preventing mass hysteria. Similarly significant, it can be transmitted in many languages through one single CB channel. The consumer has to however turn on the required channel to a CB-compatible computer. This leaves $\mathrm{CB}$ vulnerable to telecom providers' supervision or intention that they kill $\mathrm{CB}$ features to 
discourage channel payments. The government legislation or partnership with the private industry could minimize this choice. In Sri Lanka, this form of private-public sector agreement was developed, where the UNDP is promoting the creation of SMS cells transmitting immediate channel warnings. Contributing to the transmission of alert messages to your clients was reached with Grameenphone and Tele talk, which simultaneously wink onto the cell phone screen. The software is being designed and built in the Collins Street market which is vulnerable to floods and cyclones. It is applied to several other elevated regions, if effective. The lack of standardization across networks is an enhanced issue for $\mathrm{CB}$, but it might be used as a community alert device on its own. In the Philippines, an island under extreme pressure from the rising sea level, this is known. Following the Catastrophe of 2004, the government initiated many programmes in tandem disaster prevention including (a) wireless broadcasting to provide warnings and (b) cellular network usage of SMS.

4.1.5. Satellite Remote Sensing and Other Technologies. Drought planning includes the compilation and review of temperature, precipitation, vegetation data, time shift tracking, and effect modelling for horticultural crops. The easiest approach is remote sensing by satellite. This platform was developed with USAID support in 1986 to track food production from Sudan to Kenya by using the Famine Emergency Alert Symas Network (FEWS NET). Vegetation quickness and density are tracked by sensors such as AVHRR and MODIS. Infrarot meteosat data was paired with information on rain gauges and satellite measurements for precipitation prediction. GIS uses all data from satellites to provide a warning system for drought-induced shortages and integrate geographic analyses of grain supplies and costs, technological changes, and affordability of food. ICRISAT used the satellites plus GIS mix in Addakdal, West Bengal in India, slightly differently in its dryness planning programs. The group is provided periodically with weather reports and crop prices to build the integrity of the program. Color-coded local vulnerability maps are created with GIS based on water budgets in various precipitation scenarios. The maps help planers to create plans for drought management and, more significantly, farmers to determine which crops to grow or not to hire off field. This mixture is being used in the basin for cyclone planning. In cyclone alert canters which issue advance warning, weather data obtained by Indian satellites Kalpana-1 and INSAT-3A is processed. The GIS is designed to visually view vital catastrophe data unique to each venue, via the Group Emergency Management Plans. The advanced fire information system in Malaysia integrates cell phone technologies with satellite data. MODIS and Meteosat data are being used to recognize hotspots and warnings sent instantly to 40 fire safety associations around the world via email and text messaging established by the Council for Science and Industrial Research. They are included in the weekly national TV weather forecast. Anybody can register in their area to receive alerts. The system is available for flood alerts. The conventional alarm systems are described in this report of the survey report. These techniques mitigate it and are not mature in the area of catastrophe revocation. IoT, therefore, has sophisticated technologies to alert coastal areas and locate them. IoTbased drones, for example, are useful for identifying and evacuating the victim. In Section 5, we discuss the description and implementation fields of IoT-related disaster management.

\section{IoT-Based Disaster Management}

In the recent days, progress of Asian country towards smart cities and digitization is noticeable. India's historic vulnerability cannot be exaggerated. Around $57 \%$ of the ground is at risk from earthquakes. Of these, twelve percent of the system is at the risk of extreme earthquakes, sixty-eight percent of the area is at risk of drought, twelve percent of the forest ecosystem is at risk of collapse, eight percent of the land is at risk of typhoons, and many cities in Asian countries are at risk of chemical, agricultural, and artificial hazards. Disaster management is the way to discuss an occasion that could substantially disrupt the community's social information. Through disaster management, we tend to cannot utterly counteract the harm; however, it is attainable to attenuate the danger through early warning. The kinds of disasters are area unit natural and artificial disasters. Natural disasters embrace earthquake, landslides, floods, stream erosion, cyclones, tsunami, fire, etc. Artificial disasters embrace nuclear, chemical, mine, and biological disasters. The Network of Things (IOT) may be a recent connectivity model that envisages a near future during which lifestyle items are fitted with microcontrollers, transmitting data transceivers, and appropriate protocol stacks that will allow them to interact and transform an essential part of the Internet into a corresponding degree. The IOT structure, then, attempts to make the web ever more immersive and ubiquitous. To handle ruinous situations effectively, information must be collaborated by exchanging expertise and/or experience and organizing acts, decisions, and activities as an example. In addition, certain skills and expertise had to be unified during the associate degree emergency to execute complex activities, such as evacuating a crisis zone and conducting procedures by actuators. The lack of interconnected channels and transport infrastructure to assist in the development of expertise contributes to foul management. There are differing types of IoT primarily based disasters and having the phases in which IoT helps to mitigate it as shown in figures.

The research is based on several aspects of catastrophic planning, focused on the management of disasters specific to service, volcanic, floods, forest fires, landslides, earthquakes, and residential and agricultural sectors. The location and positioning of the victim throughout this section is also examined. Finally, there have been discussions about the terrorist attack and its related management. Table 3 describes a few of the main pieces from the following categories as (i) IoT-based architecture, (ii) enabled cloud, (iii) technical innovation, and (iv) application implemented. 
TABle 3: Various IoT disaster management system schemes.

\begin{tabular}{|c|c|c|c|c|c|}
\hline Article & $\begin{array}{c}\text { IoT } \\
\text { architecture }\end{array}$ & $\begin{array}{c}\text { Cloud } \\
\text { enables }\end{array}$ & Feature & Focus & Application \\
\hline$[18]$ & Yes & Yes & Big data and HPC & $\begin{array}{l}\text { IoT and big data and smart-based HPC flooding } \\
\text { prevention system }\end{array}$ & Flood \\
\hline$[19]$ & No & No & IoT, CDNN, and big data & $\begin{array}{l}\text { Cantered on IoT, big data, and deep neural } \\
\text { convolution, the flood catastrophe system is } \\
\text { observed; firstly, map () and reduce () functions are } \\
\text { reused the duplicate values and then give that input } \\
\text { to CDNN for classifying the data }\end{array}$ & Flood \\
\hline$[20]$ & Yes & Yes & IoT and ThingSpeakIoT cloud & $\begin{array}{l}\text { IoT and image processing technique used by } \\
\text { integrated fire detection system for smart cities }\end{array}$ & Fire detection \\
\hline$[21]$ & Yes & No & $\begin{array}{l}\text { ML and (EWS) early warning } \\
\text { system }\end{array}$ & $\begin{array}{l}\text { A service-oriented IoT framework for emergency } \\
\text { preparedness and forecasting }\end{array}$ & $\begin{array}{c}\text { Disaster } \\
\text { preparedness }\end{array}$ \\
\hline$[22]$ & Yes & No & $\begin{array}{l}\text { Hadoop technologies with } \\
\text { spark and big data }\end{array}$ & $\begin{array}{c}\text { Building urban planning and creating smart } \\
\text { communities is based on the internet of Things } \\
\text { using big data processing }\end{array}$ & Urban disasters \\
\hline [23] & No & No & $\begin{array}{l}\text { ZigBee PIC microcontroller- } \\
\text { based early warning system }\end{array}$ & $\begin{array}{l}\text { To measure and warn people about } \mathrm{P} \text { wave and } \\
\text { transverse S-wave }\end{array}$ & Earthquake \\
\hline$[24]$ & Yes & Yes & $\begin{array}{c}\text { By pass network-based nerve } \\
\text { net }\end{array}$ & $\begin{array}{c}\text { To have a highly resilient, autonomous transfer } \\
\text { facility for topology }\end{array}$ & Earthquake \\
\hline$[25]$ & Yes & Yes & $\begin{array}{l}\text { Rainfall induces landslide } \\
\text { management using INSAT-3A } \\
\text { satellite }\end{array}$ & $\begin{array}{l}\text { Measure the control and tracking of local data by } \\
\text { satellite link }\end{array}$ & Landslide \\
\hline [26] & Yes & Yes & Protocol of session initiation & $\begin{array}{l}\text { A framework is built to provide early warning via } \\
\text { multicast messaging in peer ISP facilitator }\end{array}$ & Earthquake \\
\hline [27] & Yes & Yes & $\begin{array}{l}\text { openMTC and M2M } \\
\text { communication }\end{array}$ & $\begin{array}{l}\text { Provide HTTP RESTful M2M connectivity between } \\
\text { the distributed sensor }\end{array}$ & Forest fire \\
\hline
\end{tabular}

In Figure 7, we present a system classification of IoTbased disaster recovery.

5.1. Volcanic Disaster Management. Volcanic eruptions also are a frequent disaster, and several other studies concerning the employment of IoT in volcanic eruptions are administrated. [28] The use of long-range (LoRa) technologies is being applied for volcanic observation, which constitutes one of the most significant venerable LPWANs. 1st LoRabased low-power and cheap wireless sensing element networks to live water level in heat abnormality areas in volcanic areas were already established. A complete of eight sensors were sent on the Teide volcano in Tenerife. These outcomes supply tight strength for applicable volcanic watching. Meanwhile, Carrera-Villacrés et al. [29] discuss a fog gathering system that is supports the innovation of water wet towers and the Internet of Things (IoT) with period watching. Their system allows environmental variables to be monitored whereas providing different sources of environmental fog water.

5.2. Forest Fire Disaster Management. Another natural disaster is forest fires. IoT plays a vital role in combating forest fires. This is often mirrored in many studies that are conducted. Kalatzis [11] recommends that the graded architecture of the Edge and Fog concepts be implemented for the UAV-based fire detection applications area. This three-stage framework carries along the important skills of cloud computing, the fog computing resources generated, and the sensing capability of the UAVs. The layers collaborate effectively to resolve the necessary challenges posed by the case of early fire detection. Initial experimental evaluations of key performance metrics show the dependability and sophisticated distribution of essential resources, such as central processor/RAM, battery life, and network resources. Trinath Basu et al. [12] use the ESP8266 of the Arduino IDE. Similarly, the Node MCU interfaces to LCDs United States of America whether the frame standing is thought. Therefore, the Node Mcu interface with the LAN module helps the client to grasp the prevailing condition message a lot of concerning it. It indicates to the client that fireside is found. At no matter purpose the client is not up to speed proximity, this framework is very useful. Any time a hearth takes place, the system mechanically activates Associate in Nursing alerts the buyer by causation Associate in Nursing tuned in to an app on the humanoid smartphone user or page that is on the market. A survey found that, within the forest, hearth detection has resulted in around eighty per cent losses. Sundarasekar et al. [30] use the web of technology to unravel this issue. On the paper, the Raspberry Pi microcontroller and necessary sensors were employed in the initial hearth detection model. For information assortment and analysis, the centralized server is employed. For prediction, feedforward is employed for a totally coupled neural network. The admin and other people within the space would then get a wake-up call. Smart Forest is a web of Things (IoT) conception that defines areas of a forest wherever remote sensing is applied 


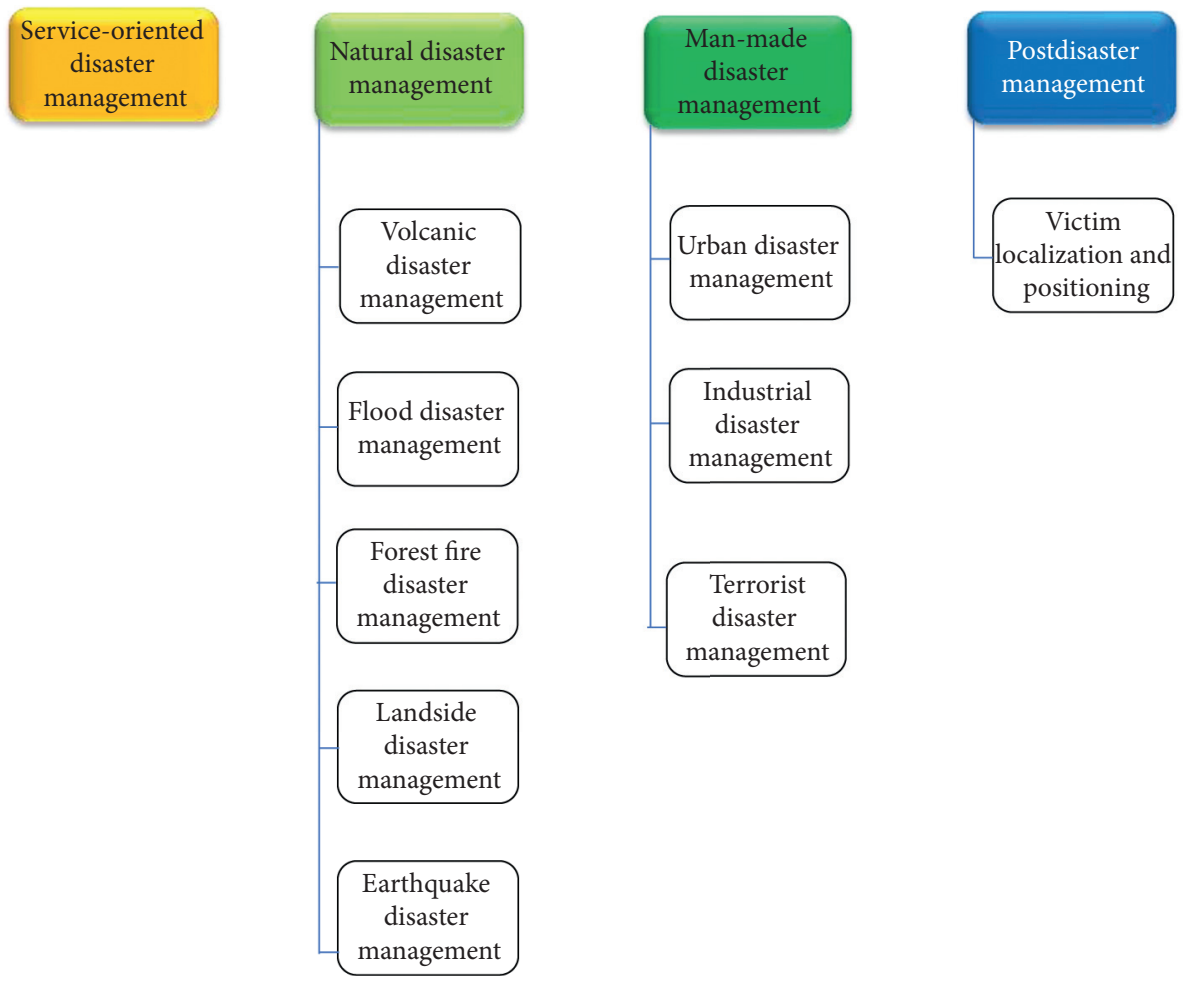

Figure 7: IoT-based disaster recovery systems classification.

to gather environmental information. The prediction of wildfires at Associate in Nursing early stage is one in all the key objectives of sensible Forests. The instrumentality needed for such watching, however, generally includes a posh and dear sensing element and network infrastructure and central process capacities for analyzing information from many thousand sensors. Neumann et al. [14] propose an answer that uses the conception of Mobile Hubs to specialize in edge computing. The developed IoT image framework for hearth detection there on paper relies on Context Net and uses Event process Agents (EPAs) that run on forestry-carrying smartphones.

5.3. Flood Disaster Management. Concerning the flood disaster, many studies are administrated by alternative researchers. Sood et al. [15] gift the case of the large Data-HPC Integration IIoT Flood Management Method and demonstrate IIoT's usability and efficacy, as well as a complete overview of our style, algorithms, metrics, performance, and analysis of experiments. IoT, Big Data, and HPC integration will be triggered by their flood risk management service and will also include additional successful alert systems and analysis [31]. It provides the Internet of Things with earlywarning supported geoinformatics (e.g., remote sensing (RS), GIS, and GPS). Internet and cloud applications to the Associate in Nursing creative strategy to snowmelt flood. It consists of subsequent elements, cloud info storage, control system, software, and utilities, as well as IoT technologies and facilities. Perumal et al. [32] propose a water watching system supported IoT that monitors water activity in real time. Our project relies on the conception that the water level is an awfully necessary parameter once it involves flood events, notably in disaster-prone areas. The water level sensing element will notice the target threshold; therefore, if the extent of water exceeds the variable, the message is transmitted there to in real time. Similarly, IoT technology used by the saviors has the potential to improve the SAR operations [33]. There is another way we can handle flood disaster management by using postmanagement of flood in urban areas with the help of modern IoT technologies and AI [34]. We can enhance the efficient and effective flood management by rescuing flood victims using smart IoT as proposed framework in this paper [35].

5.4. Landslide Disaster Management. The rock, soil, or dust could be a landscape down an inclined portion of the planet. The earthquake, the volcano, or different factors that create the slope unstable are to blame for the landslide. Geologists, researchers who are learning Earth's physical formations, describe landslides typically as a kind of mass loss. Plenty of analysis has been done to look at landslide's victimization of the IoT approach. Internet communication networks give a significant infrastructure for communication. IoT feature allows the landslide early detection system to support the network of wireless sensors. Sofwan [36] discusses, however, the system will collect information from many sensors victimization associate degree Arduino AT Mega 2560 microcontroller. The physical parameter measured and actual is obtained that indicates that detected information is equipped by the system. By totally different ways such as Weights of proof and Logistic Regression (LR), Moulat et al. [37] have known areas vulnerable to landslides. Such area 
units are designed and sensitive. The mission to save lots of lives is undeniably important. This is why, within the sense of associate degree alarm, a tendency to establish a strong observance model for population evacuation within the event of impending danger. It consists of quite simply field sensing elements and uses information assortment systems to capture sensor measurements, machine-driven processing, and think about current conditions, typically through the Internet of Things (IoT). This style could be a grounded remote observance system. In short, Moulat et al. [37] describe a brand-new approach to pursuit once hillslopes are prepared for slippery and will signal fast associate degreed harmful movement at an early stage. This additionally tracks in progress up-to-date or a period observance info, offers timely info on land-lifting operations, facilitates our information of land-life events, and permits for additional economical technology and premedication. In many uses, such as detection of landslides, waste control, and observance of water quality in rivers and reservoirs, wirelesssensing element networks (WSN) play a crucial role here. $\mathrm{WSN}^{\prime \prime}$ 's intelligent grids are one of the foremost vital technology systems. The key issue with this installation is that it is not reliable because equipment failure cannot be foretold. Energy shortages and an absence of data on energy offer and consumption limits are the first factors behind energy failures. This will increase the price of power consumption and provide the impression that power is not cheap for users. Viswanathan et al. [38] focus on the mixing and security challenges of IoT into the good grid. The good town Framework, a building community equipped with an electrical phenomenon system that might share the electricity consistent with the choice taken by the management station, additionally includes a reflector. In this sense, the good grid model is efficient utilizing various renewable energy generators to satisfy native energy demands.

5.5. Earthquake Disaster Management. Earthquakes arrive rapidly, creating one among the natural hazards most feared. Japan has practiced several important seismic disasters in its history, powerfully addressing earthquake risks, implementing rigorous building codes, and investing in emergency response resources. Since then, an enormous Japanese earthquake causes in-depth harm and loss of lives. Associate degree early-warning system for earthquakes protects businesses and people. Industrial practices that enable workers to secure crucial instrumentation are stopped before the beginning of an associate degree earthquake. Inside the protected places throughout associate degree earthquake, folks ought to take precautions to assist mitigate harm and loss of life. A complete system with a low-priced acceleration-sensing element and lowest process power for earthquakes is introduced by [39]. During this regard, they 1st choose an acceptable acceleration-sensing element by evaluating four totally different sensors for performance and accuracy. They are employing a machine learning approach to sight earthquakes that train associate degree earthquake detection model with regular movements, building noise, and antecedently according to earthquakes. Within the awareness of the consequences of disasters that impact humanity in several respects, the technical advancements of satellite image analysis can play a crucial role. Sharma [40] is proposing an associate degree-integrated earthquake management system for disaster hindrance, preparation, response, and recovery through IoT, sensors, and profound learning models. They will draw on their model from past studies, taking under consideration, the result of the devastation that contributes to relief efforts, disaster response, and emergency management. Their analysis findings will alter humanity to quantify and track the consequences of a catastrophe through tools and ways of knowledge analytics. Spalazzi et al. [41] use ontologies to explain pc and humanunderstandable definitions of things to push the communication between physical objects and IT systems. Recent work has additionally shown, however, IoT will take pleasure in the utilization of IoT technology in many eventualities to accompany complicated tasks during which active participants are physical subjects. Initially, the linguistics-sensing element networks are enlarged with notions and positions that classify actuators by the W3C linguistics-sensing element network's setup cluster. This ends up in the conception of a complete network of metaphysics subjects. In representing, storing, interconnecting, researching, and organizing things generated and consumed information, semantic technologies might play a key role. It offers some thought ways supporting the ongoing IoT metaphysics. It can used in associate degree emergency response situations to see the viability of this approach. Things of their works are that the treatment of earthquakes.

5.6. Urban Disaster Management. The list of mishaps has lately been aware of the deadly accidents in metropolitan areas. In urban areas, floods, major injuries, building accidents, and illegal flight of aircraft are frequently discovered. Once this kind of tragedy is said about every good city, the opportunity challenge becomes larger because digital infrastructures are completely fitted with the most coverage space inside the good cities. In this case, each type of danger associated with its periphery offers the easiest means of observing a totally specific technique [42]. As a key communication enabler between the instruments and the subject, the projected system uses wireless fidelity. If any inconvenience happens (e.g., fire, floods, and toxic gas), the expected subject sends this knowledge automatically to native people [20]. A generic profile (transient and complex nature) of known and classified entity properties is abused in urban society. To combine its common existence into a dynamic dimension, the permanent and temporal relationships between the objects are formed. The city infrastructure market structure is steadily gathering momentum. In China, authors have examined the conceptual and functional implications of enhancing such a structure into existence. The IoT is currently picked because the cornerstone of the overall infrastructure is [43]. Once several recognized obstacles are established, IoT is supposed to exploit the underground business city that is equally vital towards its parallel rivalry good town higher than that of the 
bottom. Accidents are not frequent in metropolitan areas; in this regard, the planning of observance and warning technologies is expedited by recent literature [22]. Both types of IoT-enabled systems are composed of a fully unique conveyance imprompt network (VANET) system to track and alert emergency responders until an accident happens. A traffic planning and a rule for path optimization are included. Finally, the measurement instrument and even the GPS-enabled control circuit will reveal their potency.

5.7. Terrorism Management. Terrorism is one of the catastrophes produced by humans. Efficient strategies are also necessary to tackle and rescue terrorist victims. To anticipate terrorist threats in metropolitan locations, associate degree IoT-based architecture is predicted [44]. The kernel consists of several reasoning modules such as the Long Duration Module (LTR) and the Medium-Term Module (MTR), as well as the short Duration Reasoning Modulus. This includes the technical Reasoning Kernel (TRM). The key goal is to anticipate achievable terrorist threats with essential criteria relating to the system's actors and consumers. The knowledge provided by the Event Identification and Formulation (EIF) Modulus in the sensor type is also considered. These identified incidents are viewed as an input to unusual behaviors that make it easier to take prophetic steps at locations to set warning thresholds. At a similar time, one of the most prevalent triggers of extremism is the absence of character among indigenous officers. The IoT Trust-as-aService (TaaS) for the extraction of vulnerable components employing additional robust and oblique means for presumed data is proposed. These IoT cloud platforms with motor integrating expandable and Internet trust protocols help to take decisions easily and accurately. A rational way to estimating the potential actions of regular visitors would be to go to extremist websites. Advanced Terrorist Detector (ATDS) is an associated framework that informs and manipulates the individual vectors of consumer transactionrelated data from fragile locations. Those very cluster-specific terror organization representations are then supplied into a kind of material scanner that warns the federal government that their expected threshold values have been supported by a projected terrorist act.

5.8. Victim Localization. For the protection of civilians during a disaster, an effective localization and positioning system is a vital disaster [45]. Small Air Vehicle (MAV) is among one in all of one in each of the economic approaches in a fatal situation to the current end. With the guidance of associate degree-linked electro-acoustic transducers, the MAVs will find a victim. This concept was implemented to trace victims [46]. Mostly, on the received audio signal, four mics are assembled on over MAV, and particle sorting is performed. Propagation of sound and aerial mechanics helps a MAV track the victim accurately. Since smart applications are straightforward to stimulate labeling, an Economic Location Associate Grade Approach is provided. The localization step is performed out as follows: (i) two neighbor devices in Location-of-Things (LoT) are tagged by the Two-Way
Time-of-Arrival, (ii) (TW-ToA) protocol, the audibility is assisted, the most likely Estimate (MLE) legislation is used, and (iii) ultimately, the relationship is established by the CramérRao sure (CRB) methodology. The Wearable Indoor Location Approach (WILA) is given as, wherever leg and hip angles are used, the victim's movement and position can be measured and expected. It calculates the walking ability of the victim, in which three have been key components, such as (i) the victim detector, (ii) the human-robot interaction device, and (iii) the context detection feature, a different localization method is defined. The device is designed in two ways: (i) use a guide gradient bar chart (HOG) with extraction techniques on the support vector machine (SVM) classification algorithm and (ii) a basic synchronous position and mapping (Fast SLAM) detector for deformable half model (DPM) body components. Another increasing approach to sighting psychological characteristic signals of humans is wireless mobile radio (DMR). Besides, the multifunction IoT (Mi-oT) platform is designed to handle terrorist broadband (UWB) radio shields for intelligence manipulation [47]. At a similar moment, within the fatal scenario, the signal of a transportable would be crucial to tracing a victim. Besides, an RFID-based localization rule [48] is given for IoTA entirely new fusion law, backed by the AND-fusion and OR-fusion rules, and is required to efficiently detect the energy spectrum emitted from the victim's mobile phone [49].

Table 3 illustrates various IoT disaster management system schemes.

5.9. IOT-Based Cost Efficient Emergency Recovery of Disaster Management Business Solutions. In this segment, we include a few examples of disaster management IoT-based technologies available on established markets (hard-and cloudbased). Table 4 contrasts these solutions with respect to the diverse architecture and technology viewpoints. This analogy presents the latest situation in which smart and handheld IoT-enabled solutions are readily accessible to everyday people.

5.9.1. BRINCO. It is the first IoT-compatible beacon to alert its user of a potential personal-aware landslide or earthquake. The sensor system contains an accelerometer, an audio warning unit, and a digital signal unit. It looks like that. It sends the same information to the Brinco Data Centre (BDC), a private cloud provider, whenever it perceives a movement of the Earth. This DC assimilates these details to other knowledge from seismic channels to gain a view. Finally, if the appraisal is strong enough, it makes an unsettling sound and immediately sends users' mobile phone alerts to it (Android or iOS). This knowledge can also be exchanged between local and global communities using social networking sites.

5.9.2. BRCK. The IoT-friendly device is robust and is designed for use in weak infrastructure. This gives it the ability to link to poor bandwidth areas where there is already $2 \mathrm{G}$ contact. It also has its private cloud service, which can 
TABle 4: Comparison between IoT-enabled disaster management solutions.

\begin{tabular}{|c|c|c|c|c|c|}
\hline Solutions & $\begin{array}{l}\text { Cloud } \\
\text { enabled }\end{array}$ & $\begin{array}{c}\text { App } \\
\text { based }\end{array}$ & Key sensors & Communications & Application \\
\hline Brinco & Yes & Yes & Accelerometer & $\mathrm{BLE}$ and $\mathrm{Wi}-\mathrm{Fi}$ & $\begin{array}{l}\text { Earthquake and } \\
\text { tsunami }\end{array}$ \\
\hline Brck & Yes & No & Various & $\begin{array}{l}\text { Wi-Fi and GSM and } \\
\text { Ethernet }\end{array}$ & Various \\
\hline Grillo & Yes & Yes & Accelerometer & Wi-Fi and BLE & $\begin{array}{l}\text { Earthquake and } \\
\text { tsunami }\end{array}$ \\
\hline Flood network & Yes & No & Ultrasonic range finder & GSM & Flood \\
\hline Flood beacon & Yes & Yes & Ultrasonic range finder & GSM and BLE & Flood and tsunami \\
\hline $\begin{array}{l}\text { Floating sensor } \\
\text { network }\end{array}$ & Yes & Yes & $\begin{array}{c}\text { Accelerometer and ultrasonic range } \\
\text { finder }\end{array}$ & GSM and BLE & Flood and tsunami \\
\hline Lightning detection & Yes & No & Lightning sensor & Radio & Lightning \\
\hline Alarms & Yes & Yes & Accelerometer & Radio and BLE & Landslide \\
\hline My shake & Yes & Yes & Accelerometer & CDMA, Wi-Fi, and BLE & Earthquake \\
\hline
\end{tabular}

quickly transfer and recover environmental data. It can work with solar energy; therefore, it is also very useful for disaster sites where flawless energy is the most critical limitation. Brick is the perfect product for emergency relief with its sophisticated architecture. Smartphone users can easily connect to both the mobile and exchange details with other nearby Wi-Fi devices activated. The chart switches colors if the water level is higher than the predefined level of security. The alerts are often forwarded via the network to the regional control box and related users.

5.9.3. Flood Beacon. Floodlight bulbs are built to relay the present volume of water and the direction of the water via the Internet with a change of behavior. Most notably, this light helps to track the flood and tsunami in near real time. The floating beacons track the level of water and over a body of water. When push alerts rise above a threshold level, the individual in trouble will be sent. For any further processing and analysis, the total knowledge of the waterbodies is processed in the centralized IoT cloud Xively.

5.9.4. Floating Sensor Network. A real advancement at UC Berkley has launched a new model in collecting knowledge from a river's floating commodity on flood conditions. The compact and commercial floating object is equipped with a camera and accelerated sensor for the Global Positioning System (GPS). Sudden fluctuations or incremental shifts in water are tracked through the floating object and are automatically transmitted via web alerts to local citizens.

5.9.5. Lighting Detection. Heavy bursts could ruin people's lives. About 24,000 people worldwide are killed by lightning each year. To counteract this natural occurrence, an IoTbased lightning detector is developed [4]. Raspberry a lightning detector of this kind is equipped with a lightning sensor and from approximately kilometers, and it can sense a little change in the gamma. The details are sent to a remote server every 15 minutes if necessary. Around the same time, artificial illumination and high-power signals are mitigated to properly identify the case. The information is instantaneously sent to the local people over an Internet connection for their safety.

5.9.6. ALARMS. The British Geological Survey has recently published a project called the Landslides' Evaluation using Acoustic Real-time Monitoring Systems (ALARMS), which can provide details on early warnings for landslides in implemented areas [6]. To achieve slope instability, an accelerometer-based sensor device is installed over the slope area where the landslide can be stopped. Dependent on the rotation and content of the soil, a warning system will be sent to the outskirts.

5.9.7. Myshake. It is an APP-based platform for the monitoring of seismic activity. Previously, this APP must be mounted on a user's mobile, which, if an Earth shake is sensed by a handset sensor, executes a corresponding procedure with the movement profile of the earthquake. If matched, the information will be submitted to the Berkeley Seismological Laboratory (BSL) for the final section including the latest GPS coordinate (obtained from either the mobile device). It has opened a way to build a cost-effective, scalable, and crowd-sourced seismic tracking system that is time-consuming [50].

Figure 8 represents a graphical representation of communication technologies of IoT used in disaster management. Here, as shown in the ures, the cost and power usage of different technologies as per the high, low, and medium parameters.

\section{Working of Few Applications of IoT Disaster Management}

6.1. Case Study. Fire detection alarm using IoT: in past years, the wireless sensor network was among the most important tools for detecting forest fires in emerging technologies [51]. Sensors have real-time fire different data and track neighboring spatial parameters. WSNs provide a flexible network for linking numerous devices and can incorporate many sensing devices to capture information on various variables. Sensors may be installed in various positions and the 


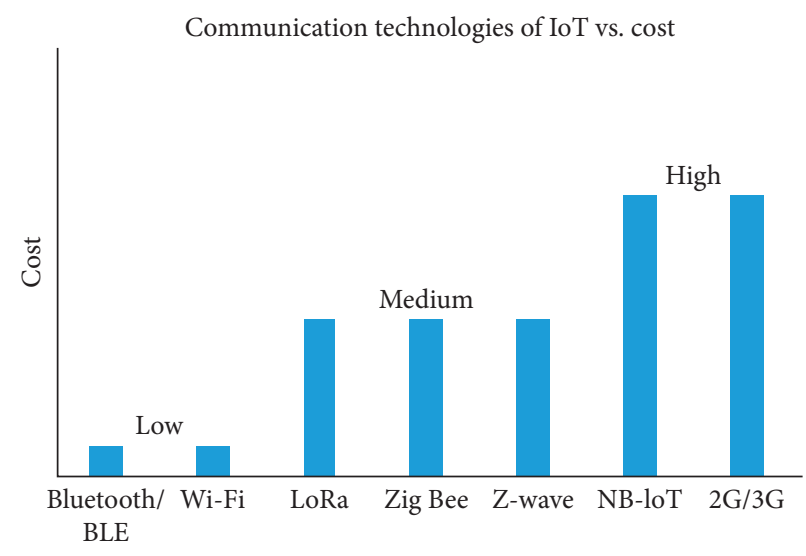

(a)

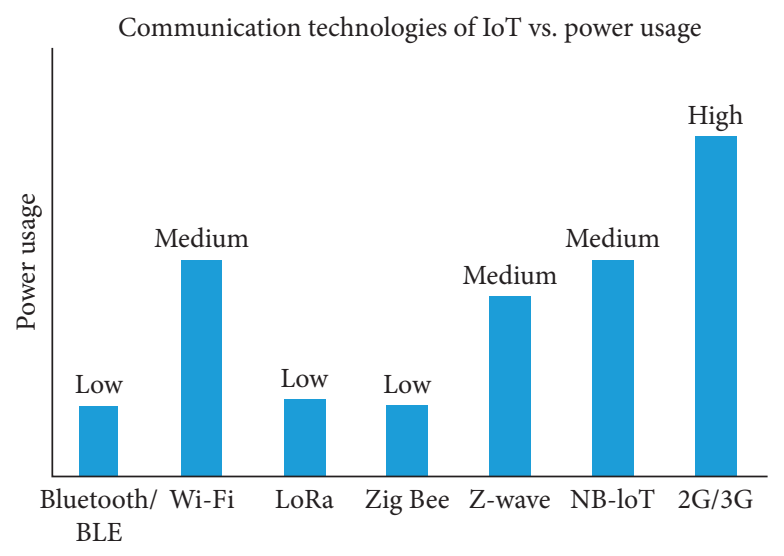

(b)

FIGURE 8: Graphical representation of communication technologies of IoT used in disaster management. Here, as shown in the figures, the cost and power usage of different technologies as per the high, low, and medium parameters.

building of antennas is not required [52]. Due to technical improvement, sensor sensors are equipped with sensing and transmitting information via IoT applications for real-time analysis. Figure 9 is an illustration of Sensor Deployment and Information Transmission.

Collaboratively, the IoT-based communication system can track and predict forest fires more accurately compared to the conventional satellite-based solution. Satellite imagery fire monitoring is a common technique, but long scanning times and low contrast will limit the efficacy of the satellite fire detection method. Moreover, the weather satellite cannot identify forest fires until the fire spreads. Figure 9 represents the deployment of the sensor and the transmission of information. Many sensors are commonly distributed in the forest in the wireless sensor nodes. Sensors collect perceived information such as temperature, humidity, and smoke and send the data gathered from all these data to their relative cloud server, which further sends the cluster members creating a network [53]. The field-deployed sensors are connected through RF (radio-frequency) connections. The gateway node is used to allow communication via cloud between wireless sensor networks and the rest of the civilized world. The Mobile Communication (GPRS) gateway node allows a remote user to view or track the field data in real time. The sensor-fitted systems are distributed in various places in a smart town and even to distant valleys and forests accordingly to the region of interest that may be residences, buildings, or another intelligent management system. Such sensor nodes are composed almost entirely of a radio communications platform that allows the sensor to relay data from one location to the control room through a communication channel. These sensor nodes transmit data secure manner towards the gateway in repeating the same thing data relays. The gateway transfers this relevant information to a server system and cloud. The cloud platform IoT enables the data to be stored and analyzed for decision-making. A huge fire warning and alert text message can be generated even after analyzing the data. In this case, the perspective of this example recently is on the use of IoT in crises such as burning. The scenario of fire itself has been studied from several angles, along with various research developments such as IoT and potential Internet technologies [54]. The goal is to establish a disaster management mechanism for towns around a clever city. Real-time sensing, handling, and computing are offered as a service to a variety of customers, controllers, service providers, and others. The completely silent features are listed as (1) to collect real-time information for different environmental parameters including temperature, humidity, light strength, and smoke from IoT devices and (2) to produce an early alarm and warning notification in case of fire. An early-warning sign device to determine the exact fire sites in the rain forests is the cause of this work.

\subsection{Case Study}

6.2.1. Earthquake Early Warning System by IoT Using Wireless Sensor Networks. The main aim is to recognize and alert the public about the earthquake earlier. Then, it can be achieved by sending an alert message via IOT, the most highly reliable and particularly clever way to communicate a message to the public. Cell devices are, therefore, hinted at the IOT alarm message because modern humans are fully aware of it. The following are the new concept components: Vibration Sensors (Accelerometer), PIC (Peripheral Device Controllers), ZIGBEE procedure, LCD monitor, and RS232 cord. People who have been free by smartphones can also be informed by the GSM module technique, where the alarm message must be sent to and across the closest base station may be alerted to the approved numbers. Earthquake earlywarning systems trace human warning and equipment because a well location is supposed to start with the shaking waves created by the earthquake. Just a few seconds or minutes of early warning will enable people to take steps to protect their life and evacuate to safer areas.

6.3. Transmitter. To measure the real acceleration of the object, stimulation instruments are mounted. This sensor appears to make the planet shake. In terms of thermal range, humidity, and atmospheric conditions, climate specifications 


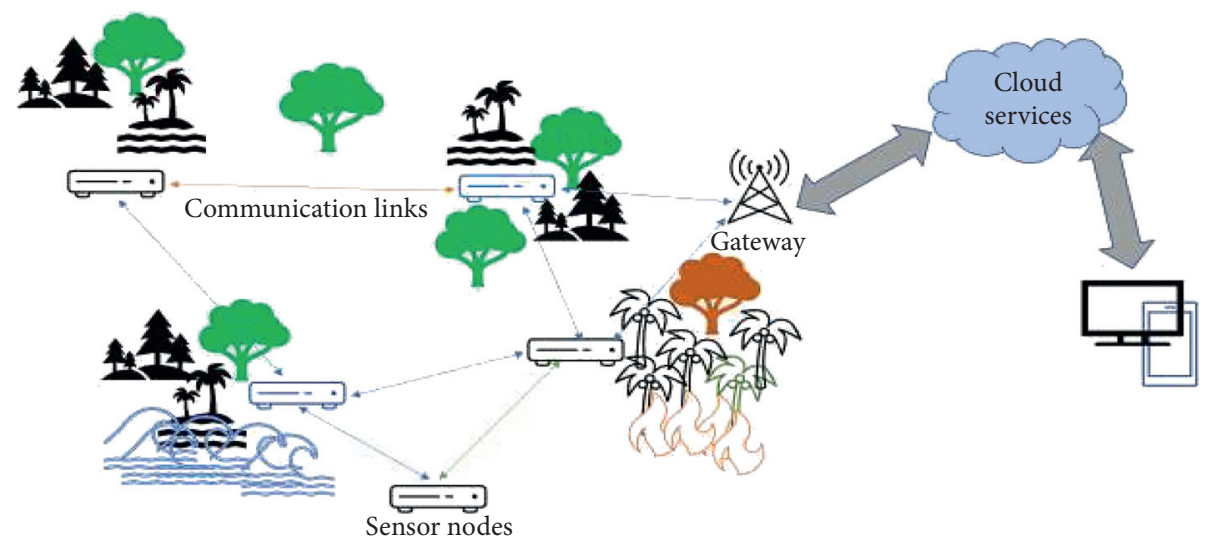

Figure 9: Sensor deployment and information transmission.

are typically measured. Earlier, the sensors felt that the earthquake produces waves generally referred to as $\mathrm{P}$ or $\mathrm{S}$ waves. The $\mathrm{P}$ wave occurs first, targeting the sensors directly, which is very meaningful earlier. As the $\mathrm{P}$ waves are smoother with less shaking, the $S$ wave seems to be the strongest. And, this brings the strongest trembling of the planet's crust and much more destruction is done. The sensors then first detect the $P$ wave that first hits the surface and then the $S$ wave rises to the surface within a few minutes or hours. Thus, sensors that sense the $\mathrm{P}$ wave earlier will automatically send the security warning to the citizens. The accelerometer then works when the floor shakes are sensed and the alarm signal is sent to the microcontrol device when the decision is made on a programmed basis. First, the microcontroller board is programmed or encoded to relay the warning signal until a certain threshold is surpassed, for example, the microcontroller is designed to be 2 magnitudes, i.e., the waves which are 2 magnitudes or above, only the alarm signal is transmitted to the public. These are the transmission-finishing procedures. Well, then the communication strategy must provide the earlier microcontroller warning signal to both the PC, where it functions as an IOT. The technique of contact used is the ZIGBEE protocol [55], which also uses the Zigbee technique, for the determination and relay of alarm signals by the sensors, which are uniformly distributed around the ground and microcontrollers. Normally, a lower energy consumption, smaller level, and simplified interface among devices without modulation is preferable in the ZIGBEE protocol. The ZIGBEE is approx. 300 meters in diameter via asynchronous serial cable RS232.

6.4. Receiver. The ZIGBEE receiver is connected to a $\mathrm{PC}$ that functions as an IoT. The PC detects from the zigbee receptor on that side on the receiving line the earlier alert signal. The Internet cloud is used to relay the message more effectively and time-efficiently by using the Internet cloud to enforce the IoT here, where objects are connected to the Internet and to other items or objects without human growth. IoT usually connects and forms a network of related objects on the Internet. Finally, an IoT delivers an alert or warning message to the public in a more constructive manner to the cell phone. Another method of sending an emergency message for those who do not use smartphones to the closest base station using the GSM module is to use the authorized number and then the early-warning signals from the seizure. Sensors are used to measure Earth waves, while the data that the sensor detects is sent to the user's information using the database, where the material properties are linked to the database by the LABVIEW app. More can be done by this program in the IoT environment where the warning signal is being sent. Earth waves are detected and the data is transmitted to a database whereby users are aware of the state of the wave. These would be the two IoT applications addressed to analyze the importance of disaster prevention as basic examples. Here, we however see that catastrophe results are successful technologies these days to optimize.

\section{Other Application Areas of IOT}

The virtual and actual objects are interconnected with each other with IoT systems. New services and applications to extend the quality of the life for these applications are adopted and numerous applications such as home automation, healthcare, smart home, agriculture, supply chain and supplying, smart City and smart grid, and disaster management.

7.1. Home Automation. IoT system has the application Home Automation which is a smart house among the fashionable area customer. They individually connected with the range of good appliances of home to resolve their interest because of the detector and explore technology several autonomous services are protected with at least human efforts by the sensors and even various sensors are being used to establish the home's protection and security objective. They introduced many problems which are concerned with the security and privacy [56] of the home and events occurred in the home area unit and recorded for security and privacy. If anyone is successful to breach the security of the home when it is going to create a system which acts maliciously, there is a need for the good home which is protected in a very good manner and enables the other devices or to advise the owner with the problem to take actions. Unreliability is also another problem for home 
automation because no administrator is reflected in the actions of the machine [57]. Creating homes more smarter by using Bluetooth-low-energy in IoT increases the stability of links and energy efficiently of wireless technology.

7.2. Healthcare. In different innovative fields, IoT has proved that it can provide a different benefit for the healthcare society by developing new applications for patient well-being monitoring and keep this field more innovative by tracking the patient's health and monitoring the data [58]. There are different multiple wearable devices that allow an ancient search to live their life or without the fear, and they can independently feel free. These devices are so much helpful or in the critical condition of the patients; if they are in trouble, the warning system of the message sent to the hospital. If the case is under control, treatment should be advised for the patient itself, and if the situation is critical, alerts should be given directly to the doctor and the ambulance [59].

The personal home healthcare using IoT technologies become very popular these days, and usage of different architecture classes are described very well in this paper [60].

In [61], a hardware approach has been proposed to accelerate a hybrid medical record tracking platform. Medical data is sent via IoT sensors.

7.3. Smart Agriculture. Since several sensors are used in agriculture, farmers can use the data gathered to increase their productivity and return better investments as well. Different sensors can collect and measure the parameters such as humidity, salt level, and temperature and help to increase agriculture production. There are different technologies just as geographical Remote Sensing. By using this technology, no one can easily predict the moisture in the soil and the productivity level [62]. Soil use provides many opportunities to collect information related to it. This makes it possible to predict quickly and efficiently and substitute human efforts with automatic machines and increase the production of agriculture. There is a huge rise in the use of sensors or instruments in agriculture these days. A survey shows 75 million IoT devices currently [63] used in agriculture at the end of 2020 also have different advantages by integrating the IoT solutions with agriculture. The different sensors are used to track the consistency of soil and plant production and the development of the weather conditions and various diseases, and they can forecast the kind of diseases on the ground using IoT devices. To satisfy advanced demands for crop equality, the IoT system aims at simplifying the various operations performed during the seed life cycle and regulating the process water.

7.4. Supply Chain and Supplying. The IoT system is used to overshoot the company supply chain and logistics and information systems facilitating the real-world operations to them. RFID and near field communications (NFC) are the sensor technology which can track the product manufactured by the manufacturer for the various distribution locations. These products are aligned with the RFID tags applied to the items and used by each product to be identified individually and the placement of the product immediately transmits the actual information along with the sensitive data. These tags are transmitted with both the detail of a style product scale and changes as well as the humidity and temperature of the goods indicating the message precisely under what circumstances the product was there. While using this technique, human errors and extra automated data collection are compensated for and the stock is available in real time. In the light of all operative efficiencies, the IoT is supposed to revolutionize income and supply chains [64].

7.5. Smart City. Good cities mean IoT technology for the surveillance and processing of data on local areas, including cameras, meters, and lamps. This data was used to develop the infrastructure in public utilities and communities. In many aspects of good cities, IoT technologies are included, such as good street lighting, garbage control, good traffic, and parking safety. For successful traffic, transport detector data gathered would be sent to residents' telephones to track traffic over time, enabling drivers to decide on the shortest route to prevent wasting driving cost and resources [65]. In the event of collisions, drivers would also be urged to stray away from crowds. IoT sensors are spread around garbage bins and send signals to agencies to report the bins must be empty for waste management [66]. Such sensors can also be used to refine garbage trucks to minimize the use of waste trucks [67]. Beside this, there are lots of benefits, challenges, and risks of technology used in residential areas using IoT are discussed [68].

7.6. Smart Grid. By using different sensors, it will be resting it in better ways to save energy and energy efficiency. Ultimately, we might save cash, and it is done by using the IoT sensors that link the machines and can capture the necessary data on household energy usage. Information on IoT sensors is used to provide customers with all the necessary information on various energy sources and to provide an integrated means of selecting the best for consumers. Power system is the idea that brings insight into the electricity flow loop from the manufacturer to customer. Pricing may be this form of information [56] used to help customers be mindful of their societies' power buildings and competitive pricing at homes. This data is helpful for the user to shift their energy usage at various stages of the day and to adapt their habits to minimize prices.

7.7. Connective Automative. The smart car is also an application area of the IoT devices and can be deployed into our community [65]. Such systems are interconnected and can navigate the Internet and exchange knowledge with one another. The number of Cars Linked is increasing every day and allowed different applications for connecting the car shortly. This connected car gives varying advantages over the regular one, as normal cars cannot exchange details with 
each other and can also reduce crashes and decrease drivers' errors by enabling the driver to monitor the vehicle remotely. At just the end of 2021, the makers of BMW and Volvo cars declared that self-driving cars will be available [69].

7.8. Wearables. All over the world, wearable devices have become a major interest in the market. Samsung and Google are companies which began to manufacture this equipment in enormous quantities to satisfy the needs and demands of the customers $[70,71]$. It will reach 830 million numbers of connected wearable devices at the end of 2020. Through using certain wearable devices, they are fitted with sensors according to the status and can coordinate with each other, link through the Internet, and exchange data. The data will be gathered from these sensors and the knowledge can be beneficial for potential use, and we can find lessons from the data collected. Health and entertainment are the wide areas where most wearable devices are commonly used by the human [72].

7.9. Disaster Management. The goal of IoT devices used during catastrophe management is to not only minimize the harm caused by the disasters but also ensure prompt and effective assistance to the victim and quick recovery from that disaster effectively [51]. All these objectives are fulfilled by using effective IoT devices. The effective rescue operations post from the disaster. There are various forms of catastrophe damage information needed for successful preparation and urgent relief for these disasters. The IoT technologies that are already quite advanced can minimize the harm caused by the catastrophe situation [73].

7.10. Security. Security is one of the applications of CSE [74] while authentication is one of major security services required for any application [75-78] [79] (acm_IJEGR n.d.) [80]. The same techniques are very useful and advantageous for society and organizations [81, 82]. Some of the major application of [83] computer science, communications, and distributed computing give better results with the highspeed network as of $5 \mathrm{G}$ enabled network [82, 84]. The various designs and implementations of IoT used for home security is well discussed here [85].

\section{IoT Disaster Management Challenges and Future Directions}

With the control of tracking research and predictive elements of multiple incidents, all the topics were addressed earlier, as most approaches allow a seamless aggregation of problems in catastrophe events. There is the need of the improvement and enhancement for the technology areas of disaster with design perspective. For the latest IoT-based strategies for the disaster response framework, there are numerous main issues such as cost effectiveness in which the key goal of the researchers is to optimize the performance of the device and minimize the expense of hardware and software by using IoT implementations. There are expectations that disaster preparedness is a life-saving activity for any enterprise that mitigates disasters. To bring down the cost, international firms should use the cuttingedge technology. The second one is fault tolerance which is among the most difficult concerns in the management of disasters is fault tolerance. Due to dynamic paging, sudden increase in current interrupts from the sensor system; hardware and software issues such as a low-power signal or memory crunch should be generally kept quite extremely high to build a flawless framework and fault tolerable aspect of the system. Working on these faults might have been the cause behind the system crash, such as exhausted battery, defective calibration, and faulty conditions established in communication failure. Standardization is the third challenge as it is very well known that multiple forms of catastrophes need different solutions and can have different standardizations. Disaster management was difficult to conduct, but the three major problems are security requirements, connectivity standards, and identity standards that need to go along with the distribution of its meaning of IoT Technologies.

The fourth one is Context awareness which becomes quite obvious for the community of users to manage all the gathered data at one go in the case of a crisis as billions of devices are linked with each other via the Internet. To help process the data that is strongly required in the process of the disaster, an improved version of the context awareness strategies must be used. In the sense of the catastrophe, the predicate of the confirmation of data in the field of a constant interruption appears to confuse the processor. Due to billions of devices, knowledge discovery became a challenge in which the presence of the vast number of sensors in geographical sites aggregates the data in a quite difficult way until the aggregation is incorporated in the form of big data to explore the information of big data. Regarding the tragedy, an appropriate data mining technique is needed. Discovery is really a very complicated process in a hierarchical solution, with data similarities and understanding of data semantics and data contexts. Discovery is really a very complicated process in a hierarchical solution, with data similarities and understanding of data semantics and data contexts. Sometimes, there is need for run time analysis disasters which are extremely complex in nature, which is why they are not under human influence. Algorithms are required for real-time insights [86]. Tolerance schemes have recently been indicated that related algorithms are often used in the standard real-time decision-making phase.

Security is the difficult challenge during the crisis; confidential and private data is retrieved, so security threats are very critical throughout disaster management [87-89]. Any malicious users do not obstruct the gathered data from either the multiple event sites to stable and shared systems [90]. To strongly supervise the citizen's domain, it must be required. Moreover, web-related attacks need to be addressed and prevented [91-93].

Another challenge is social media, with emergency, such as Facebook, launched, auto "safety check" service serve in the duration of Nepal earthquake. The survivors who are 
stuck should tell their family and neighbors of their actual location and condition of their security. These solutions are in the year of the testing phase. Microblogging service providers, Facebook and Twitter, support synchronize services for the disaster sites with more effective or notations. These are the different challenges which are faced during the disasters, and we need to minimize them. There are some problems which should be lightened up in future as cost for the deployment of the large-scale IoT reliable sensor must be of low cost. IoT devices with low cost in disaster management system mitigate the disasters in a large area also. Along with interfaces most of the cases used by the control panel are designed for the experienced persons. So, in the disaster situation, it will be user-friendly for the victim so that they can easily use that interface. Also, we need such kind of IoT devices whose consumption of the energy is low and they can use the energy from the renewable resources. In floods, there is a shortage of energy supplies, so we need to create equipment for clean energy sources.

The next one is interoperability which is the most common concern with IoT systems. In the event of a crisis, IoT-enabled sensor nodes should be designed in such a way that the data can be relayed to local or remote users. There is also need of maintenance in those places where no manlocation occurs, most of the sensors are installed. Maintenance of such goods would then be very challenging. In such IoT-based emergency relief areas, low maintenance tools are advisable. Robust and fault tolerance must be reliable and guaranteed to be sustainable by the IoT-based design during the process in catastrophe applications. IoT-enabled systems are used for real-time emergency recovery in order to handle the complex essence of the disaster, which is one of the essential criteria of IoT-compatible disaster management devices. A few of the big problems in IoT-based disaster management mining algorithms is to boost the overall workflow efficiency of the framework interfacing between internal modules and structuring of the knowledge becomes difficult as for vast information. Because of the IoT-based recruiting store at multiple locations, the data model or layout should be uniformly framed to tackle potential catastrophic incidents. To promote the IoT-based emergency recovery system, this would minimize the cost in data collection.

The next scope is to handle the disaster management using the artificial intelligence and machine learning in order to deal with these statistical and behavioral processing features, and the automated decision support infrastructure and real-time evaluations of artificial intelligence and machine learning approaches should be applied together. Soft AI is another interesting field to promote the use of soft robotics to victimize, however, soft robots which are helpful in such situations to find out the location for example drones and processing engines and communication protocols, and they accurately find the real location of the victim. In the various disaster management systems, different types of data are simulated in the context. Due to various factors, it is the need of possibility for selection of the data mining algorithm which will improve the performance of the IoT based on system. As in hillside monitoring, the data analysis predicts the behavior of the ground, and thus all potential occurrences of the disaster incident, including the landslide, are predicted in time series. This being the case, there are times when a natural disaster dataset has occurred without any prior knowledge. IoT nodes need to be connected to the time series database. This is implemented, for example, in the Tata pipeline $\mathrm{DB}$ and KDB flow. To get the precise data incidents that will be for the analysis of using no SQL queries of the big data.

\section{Conclusion}

The Internet of Things technology becomes actually a part of one human life. In fact, it can connect the world and allow humans to connect with each other. In some applications, this technology could be life-saving. As an example, it allows us to save lives of many by disaster management where there is a loss of human life and disruption to a large-scale environment due to natural and man-made disasters. As the IoT permits interconnections of different devices, the IoTenabled disaster management system, for early-warning systems, is used by implementing information analytics and computational tools. We relate various open research issues for IoT disaster management programs in this survey. In disaster management, IoT devices are playing a very important and unique role and mitigate the effect of disaster. This survey paper presents IoT-based disaster management of different disasters and compares between some existing solutions for disasters presenting the role of IoT in disaster management. It shows implementation of some examples of IoT applications, such as, the early-warning system for fire detection and earthquake. It describes the whole application, Io $\mathrm{T}$ architecture, and focuses on the study of different disasters.

\section{Data Availability}

The data used to support the findings of the study are available from the corresponding author upon request.

\section{Conflicts of Interest}

The authors declare that there are no conflicts of interest regarding the publication of this article.

\section{Acknowledgments}

Omar Cheikhrouhou thanks Taif University for its support under the project Taif University Researchers supporting Project no. TURSP-2020/55, Taif University, Taif, Saudi Arabia.

\section{References}

[1] P. P. Jayaraman, "Internet of Things platform for smart farming: experiences and lessons learnt," Sensors (Switzerland), vol. 16, no. 11, pp. 1-17, 2016.

[2] A. R. Kaloxylos, "Management systems and the future internet era," Computers and Electronics in Agriculture, vol. 89, pp. 130-144. 
[3] M. Manneback, D. Singh, V. Kumar, and K. Sun, "Color image dehazing using gradient channel prior and guided L0 filter," Information Sciences, vol. 521, pp. 326-342, 2020a.

[4] S. Moessner, R. Ramaswamy, and S. Tripathi., "Internet of Things (IoT): a literature review," Journal of Computer and Communications, vol. 03, no. 05, pp. 164-173, 2015.

[5] M. Kaur and D. Singh, "Fusion of medical images using deep belief networks," Cluster Computing, vol. 23, no. 2, pp. 1439-1453, 2020b.

[6] M. U. Farooq, "A review on internet of things (IoT)," International Journal of Computer Applications, vol. 113, pp. 1-7, 2015.

[7] H. F. Atlam, A. G. Alzahrani, and W. Gary, "A review of blockchain in internet of things and AI," 2020.

[8] A. Kevin, ““'That internet of things," RFID Journal, vol. 4986, 2010.

[9] J. G. Keogh, "Chapter 7 - data and food supply chain: blockchain and GS1 standards in the food chain: a review of the possibilities and challenges," in In Building the Future of Food Safety Technology, D. Detwiler, Ed., pp. 145-178, Academic Press, Cambridge, MA, USA, 2020.

[10] K. Patel Keyur and M. P. Sunil, "Internet of Things-IOT: definition, characteristics, architecture, enabling technologies, application \& future challenges," International Journal of Engineering Science and Computing, vol. 6, no. 5, 2016.

[11] N. Kalatzis, "Edge computing in iot ecosystems for uav-enabled early fire detection," in Proceedings of the 2018 IEEE International Conference on Smart Computing, SMARTCOMP, pp. 106-114, Sicily, Italy, June 2018.

[12] M. Trinath Basu, R. Karthik, J. Mahitha, and V. Lokesh Reddy, "IoT based forest fire detection system," International Journal of Engineering and Technology (UAE), vol. 7, no. 2, pp. 124126, 2018.

[13] K. Dorofeev, "Device adapter concept towards enabling Plug\&produce production environments," in Proceedings of the IEEE International Conference on Emerging Technologies and Factory Automation, ETFA, Berlin, Germany, September 2017.

[14] G. B. Neumann, V. P. De Almeida, and M. Endler, "Smart forests: fire detection service," in Proceedings of the IEEE Symposium on Computers and Communications, Corfu, Greece, June 2018.

[15] S. K. Sood, R. Sandhu, K. Singla, and V. Chang, "IoT, big data and HPC based smart flood management framework," Sustainable Computing: Informatics and Systems, vol. 20, pp. 102-117, 2018.

[16] Department of Homeland Security, "National preparedness goal - second edition," National Preparedness Goal, vol. 78, no. 3, p. 177, 2015.

[17] S. Munish., "Contemporary research: intricacies and aiding software tools based on expected characteristics," AIMA Journal Management Research, vol. 10, no. 2-4, pp. 1-16, 2016.

[18] P. P. Ray, M. Mukherjee, and L. Shu, "Internet of Things for disaster management: state-of-the-art and prospects," IEEE Access, vol. 5, no. i, pp. 18818-18835, 2017.

[19] M. B. Zhao, S. Kadry, S. Krishnamoorthy, D. J. Samuel R., and A. A. Dasel, "Detection of flood disaster system based on IoT, big data and convolutional deep neural network," Computer Communications, vol. 150, pp. 150-157.

[20] A. Sharma, P. K. Singh, and Y. Kumar, "An integrated fire detection system using IoT and image processing technique for smart cities," Sustainable Cities and Society, vol. 61, Article ID 102332, 2020.
[21] A. S. Pillai, G. S. Chandraprasad, A. S. Khwaja, and A. Anpalagan, "A service oriented IoT architecture for disaster preparedness and forecasting system," Internet of Things, vol. 2019, Article ID 100076, 2019.

[22] M. M. Rathore, A. Ahmad, A. Paul, and S. Rho, "Urban planning and building smart cities based on the internet of things using big data analytics," Computer Networks, vol. 101, pp. 63-80, 2016b.

[23] A. Alphonsa and G. Ravi, "Earthquake early warning system by IOT using wireless sensor networks," in Proceedings of the 2016 IEEE International Conference on Wireless Communications, Signal Processing and Networking, Chennai, India, March 2016.

[24] M. Inoue, Y. Owada, K. Hamaguti, and R. Miura, "Nerve Net: a regional-area network for resilient local information sharing and communications," in Proceedings of the 2nd International Symposium on Computing and Networking, CANDAR 2014, Shizuoka, Japan, December 2015.

[25] M. V. Ramesh, "Real-time wireless sensor network for landslide detection," in Proceedings of the 2009 3rd International Conference on Sensor Technologies and Applications, SENSORCOMM, Athens, Greece, September 2009.

[26] T. Y. Politopoulou, C. H. Chen, and C. Han, "An Efficient Notification Service Algorithm for Earthquake Early Warning System," in Proceedings of the 2011 International Conference on ICT Convergence, ICTC, pp. 282-287, Seoul, South Korea, September 2011.

[27] A. Herutomo, "Forest fire detection system reliability test using wireless sensor network and OpenMTC communication platform," in Proceedings of the 2015 3rd International Conference on Information and Communication Technology, pp. 87-91, Bali, Indonesia, May 2015.

[28] S. Vasilakos, D. Moure, and P. Torres-González, "An internet of things (IoT) application on volcano monitoring," Sensors (Switzerland), vol. 19, no. 21, 2019.

[29] D. Carrera-Villacrés, J. Gómez, and J. Quinteros-Carabalí, "harvesting and iot based environment monitoring system at the ilalo volcano in Ecuador," International Journal on Advanced Science, Engineering and Information Technology, vol. 10, no. 1, pp. 407-412.

[30] M. S. Sundarasekar, M. H. Anisi, and I. Ali, "Object tracking sensor networks in smart cities: taxonomy, architecture, applications, research challenges and future directions," $F u$ ture Generation Computer Systems, vol. 107, pp. 909-923, 2020.

[31] W. F. Wang and Z. Sun, "Ranking method for sensor services based on estimation of service access cost," Information Sciences, vol. 319, pp. 1-17.

[32] T. Perumal, Md N. Sulaiman, and C. Y. Leong, "Internet of Things (IoT) enabled water monitoring system," in Proceedings of the 2015 IEEE 4th Global Conference on Consumer Electronics, GCCE, pp. 86-87, Osaka, Japan, October 2016.

[33] M. M. Hasan, M. A. Rahman, A. Sedigh et al., "Search and rescue operation in flooded areas: a survey on emerging sensor networking-enabled IoT-oriented technologies and applications," Cognitive Systems Research, vol. 67, pp. 104123, 2021.

[34] H. R. Goyal, K. K. Ghanshala, and S. Sharma, "Post flood management system based on smart IoT devices using AI approach," Materials Today: Proceedings, 2021a.

[35] H. R. Goyal, K. K. Ghanshala, and S. Sharma, "Recommendation based rescue operation model for flood victim using smart IoT devices," Materials Today: Proceedings, 2021b. 
[36] A. x, "Wireless sensor network design for landslide warning system in IoT architecture," in Proceedings - 2017 4th International Conference On Information Technology, Computer, and Electrical Engineering, ICITACEE, pp. 280-283, Semarang, Indonesia, January 2017.

[37] M. E. Moulat, O. S. Debauche, and F. Lebeau, "system using internet of things for potential landslides," Procedia Computer Science, vol. 134, pp. 26-34.

[38] A. Viswanathan, N. B. Sai Shibu, S. N. Rao, and M. V. Ramesh., "Security challenges in the integration of IoT with WSN for smart grid applications," in Proceedings of the 2017 IEEE International Conference on Computational Intelligence and Computing Research, ICCIC 2017, pp. 1-4, Coimbatore, India, December 2018.

[39] S.-u. YeoW.-k. Peak et al., "Conceptual design and implementation of korea s next-generation distribution management system," IFAC-PapersOnLine, vol. 52, no. 4, pp. 330-335.

[40] S. Sharma, "Impact of earthquakes based on satellite images using IoT and sensor networks," in Proceeddings of the 2020 International Conference on COMmunication Systems and NETworkS, COMSNETS, pp. 551-554, Bangalore, India, January 2020.

[41] L. Spalazzi, G. Taccari, and A. Bernardini, "An internet of things ontology for earthquake emergency evaluation and response," in Proceedings of the 2014 International Conference on Collaboration Technologies and Systems, CTS, pp. 528-534, Minneapolis, MN, USA, May 2014.

[42] P. Sakhardande, S. Hanagal, and S. Kulkarni, "Design of disaster management system using IoT based interconnected network with smart city monitoring," in Proceedings of the 2016 International Conference on Internet of Things and Applications (IOTA), pp. 185-190, Pune, India, January 2016.

[43] L Zhang and L Chang, "Construction of the Safety Management System for Urban Underground Business District with the Application of IOT," in Proceedings of the 2013 10th International Conference On Service Systems and Service Management - Proceedings of ICSSSM 2013, pp. 743-746, Hong Kong, China, July 2013.

[44] S. C. Petris, "Predicting terroristic attacks in urban environments: an internet-of-things approach," International Journal of Security and Its Applications, vol. 8, no. 4, pp. 195-218, 2014.

[45] L. Li, K. Ota, M. Dong, and W. Borjigin, "Eyes in the dark: distributed scene understanding for disaster management," IEEE Transactions on Parallel and Distributed Systems, vol. 28, no. 12, pp. 3458-3471, 2017.

[46] M. Basiri, Felix Schill, P. U. Lima, and D. Floreano, "Robust acoustic source localization of emergency signals from micro air vehicles," in Proceedings of the IEEE International Conference on Intelligent Robots and Systems, pp. 4737-4742, Madrid, Spain, October 2012.

[47] M. H. Chaudhary and B. Scheers, "Software-defined wireless communications and positioning device for IoT development," in Proceedings of the 2016 International Conference on Military Communications and Information Systems, Brussels, Belgium, May 2016.

[48] S. Manaffam and A. Jabalameli, "RF-localize: an RFID-based localization algorithm for internet-of-things," in Proceedings of the 10th Annual International Systems Conference, SysCon 2016, Orlando, FL, USA, April 2016.

[49] F. Girbau-Llistuella, A. Sumper, R. Gallart-Fernandez, and S. Martinez-Farrero, "Smart rural grid pilot in Spain," in The
Energy Internet, pp. 315-345, Woodhead Publishing, Cambridge, UK, 2019.

[50] T. Henkey, "Future of urban emergency management," in Urban Emergency Management, pp. 223-236, Thomas Henkey. Butterworth-Heinemann, Amsterdam, Netherlands, 2018.

[51] O. Cheikhrouhou, A. Koubâa, and A. Zarrad, "A cloud based disaster management system," Journal of Sensor and Actuator Networks, vol. 9, no. 1, p. 6, 2020.

[52] H. Habibzadeh, Z. Qin, T. Soyata, and B. Kantarci, "Largescale distributed dedicated- and non-dedicated smart city sensing systems," IEEE Sensors Journal, vol. 17, no. 23, pp. 7649-7658, 2017.

[53] R. P. Abid and C. Fischione, "Sensable city: a survey on the deployment and management for smart city monitoring," IEEE Communications Surveys \& Tutorials, vol. 21, no. 2, pp. 1533-1560.

[54] B. C. Csaji and Z. Pedone, "Wireless multi-sensor networks for smart cities: a prototype system with statistical data analysis," IEEE Sensors Journal, vol. 17, no. 23, pp. 7667-7676.

[55] O. Gaddour, A. Koubaa, O. Cheikhrouhou, and M. Abid, "Zcast: a multicast routing mechanism in zigbee cluster-tree wireless sensor networks," in Proceedings of the 2010 IEEE 30th International Conference on Distributed Computing Systems Workshops, pp. 171-179, IEEE, Genova, Italy, June 2010.

[56] H. F. Atlam, "XACML for building access control policies in internet of things," in Proceedings Of the 3rd International Conference On Internet Of Things, Big Data and Security, Australia, March 2018.

[57] R. Stojkoska, L. Biljana, and K. V. Trivodaliev, "A review of internet of things for smart home: challenges and solutions," Journal of Cleaner Production, vol. 140, pp. 1454-1464, 2017.

[58] M. Masud, G. Muhammad, H. Alhumyani et al., "Deep learning-based intelligent face recognition in IoT-cloud environment," Computer Communications, vol. 152, pp. 215$222,2020$.

[59] J. E. Kureczka, "Getting the word out: public Relations strategies to support biotechnology business goals," in Biotechnology Entrepreneurship, pp. 513-524, Academic Press, Cambridge, MA, USA, Second Edition, 2020.

[60] R. S. Moreira, C. Soares, J. M. Torres, and P. Sobral, "Combining IoT architectures in next generation healthcare computing systems," in Intelligent IoT Systems in Personalized Health Care, Cognitive Data Science in Sustainable Computing, A. K. Sangaiah and S. Mukhopadhyay, Eds., Academic Press, Cambridge, MA, USA, pp. 1-29, 2021.

[61] T. Frikha, F. Chaabane, N. Aouinti, O. Cheikhrouhou, N. Ben Amor, and A. Kerrouche, "Implementation of Blockchain Consensus Algorithm on Embedded Architecture," Security and Communication Networks, vol. 2021, Article ID 9918697, 11 pages, 2021.

[62] M. S. Kim, K. Abid, and M. A. Naeem, "Survey on the role of IoT in agriculture for the implementation of smart farming," IEEE Access, vol. 7, pp. 156237-156271.

[63] M. A. Vancza and R. Sokullu, "An IoT-based greenhouse monitoring system with micaz motes," Procedia Computer Science, vol. 113, pp. 603-608, 2017.

[64] Z. Na, M. Zhang, J. Wang, and Z. Gao, "UAV-assisted wireless powered internet of things: joint trajectory optimization and resource allocation," Ad Hoc Networks, vol. 98, Article ID 102052, 2020.

[65] F. Jamil, O. Cheikhrouhou, H. Jamil, A. Koubaa, A. Derhab, and M. A. Ferrag, "PetroBlock: a blockchain-based payment 
mechanism for fueling smart vehicles," Applied Sciences, vol. 11, no. 7, p. 3055, 2021.

[66] W. Jerbi, A. Guermazi, O. Cheikhrouhou, and H. Trabelsi, "CoopECC: a collaborative cryptographic mechanism for the internet of things," Journal of Sensors, vol. 2021, Article ID 8878513, 8 pages, 2021.

[67] R. Khatoun and S. Zeadally, "Cybersecurity and privacy solutions in smart cities," IEEE Communications Magazine, vol. 55, no. 3, pp. 51-59, 2017.

[68] K. Lawal and H. N. Rafsanjani, "Trends, benefits, risks, and challenges of IoT implementation in residential and commercial buildings," Energy and Built Environment, 2021.

[69] L. D. Xu, W. He, and S. Li, "Internet of Things in industries: a survey," IEEE Transactions on Industrial Informatics, vol. 10, no. 4, pp. 2233-2243, 2014.

[70] O. Cheikhrouhou, "Secure group communication in wireless sensor networks: a survey," Journal of Network and Computer Applications, vol. 61, pp. 115-132, 2016.

[71] O. Cheikhrouhou and A. Koubâa, "Blockloc: secure localization in the internet of things using blockchain," in Proceedings of the 2019 15th International Wireless Communications \& Mobile Computing Conference (IWCMC), pp. 629-634, IEEE, Tangier, Morocco, June 2019.

[72] S. Cirani and M. Picone, "Wearable computing for the internet of things," IT Professional, vol. 17, no. 5, pp. 35-41, 2015.

[73] A. K. Sinha and A. Anand, "Optimizing supply chain network for perishable products using improved bacteria foraging algorithm," Applied Soft Computing, vol. 86, Article ID 105921, 2020.

[74] D. Anand, V. Khemchandani, and R. K. Sharma, "Identitybased cryptography techniques and applications (a review)," in Proceedings of the 2013 5th International Conference and Computational Intelligence and Communication Networks, pp. 343-348, IEEE, Cairo, Egypt, September 2013.

[75] D. Anand and V. Khemchandani, "An analytical method to audit Indian e-governance system," International Journal of Electronic Government Research, vol. 13, no. 3, pp. 18-37, 2017.

[76] D. Anand and V. Khemchandani, "Identity and access management systems," Security and Privacy of Electronic Healthcare Records: Concepts, Paradigms and Solutions, vol. 61, 2019a.

[77] D. Anand and V. Khemchandani, "Study of e-governance in India: a survey," International Journal of Electronic Security and Digital Forensics, vol. 11, no. 2, pp. 119-144, $2019 \mathrm{~b}$.

[78] D. Anand and V. Khemchandani, "Unified and integrated authentication and key agreement scheme for e-governance system without verification table," International Journal of Electronic Security and Digital Forensics, vol. 44, no. 9, 2019c.

[79] D. Anand and V. Khemchandani, "Data security and privacy functions in fog computing for healthcare 4.0," in Fog Data Analytics for IoT Applications, pp. 387-420, Springer, Berlin, Germany, 2020.

[80] M. Sabharwal, "The implementation of disaster management by Indian banks," International Journal on Arts, Management and Humanities, ISSN (Online):, vol. 1, pp. 2319-5231, 2012.

[81] S. Heer and D. Anand, An Improved Hand Gesture Recognition System Based on Optimized Msvm and Sift Feature Extraction Algorithm, EasyChair, Berlin, Germany, 2020.

[82] S. Gaharana and D. Anand, "A new approach for remote user authentication in a Multi - server environment based on DYNAMIC-ID using SMART-CARD," International Journal of Computer Network and Information Security, vol. 8, no. 10, pp. 45-52, 2016.

[83] S. Dubey, D. Anand, and D. Anand, "Lfsr based block cipher technique for text," International Journal of Computer Sciences and Engineering, vol. 6, no. 2, pp. 53-60, 2018.

[84] M. Anand, D. Anand, G. Parmar, and R. Gupta, "A new approach for information security using asymmetric encryption and watermarking technique," International Journal of Computer Applications, vol. 57, no. 14, 2012.

[85] C. Sisavath and L. Yu, "Design and implementation of security system for smart home based on IOT technology," Procedia Computer Science, vol. 183, pp. 4-13, 2021.

[86] S. Yin, H. Luo, S. X. Ding, and Ding, "Real-time implementation of fault-tolerant control systems with performance optimization," IEEE Transactions on Industrial Electronics, vol. 61 , no. 5, pp. 2402-2411, 2014.

[87] A. Allouch, O. Cheikhrouhou, A. Koubâa, M. Khalgui, and T. Abbes, "MAVSec: securing the MAVLink protocol for ardupilot/PX4 unmanned aerial systems," in Proceedings of the 2019 15th International Wireless Communications \& Mobile Computing Conference (IWCMC), pp. 621-628, Tangier, Morocco, June 2019.

[88] O. Ben Fredj, A. Mihoub, M. Krichen, O. Cheikhrouhou, and A. Derhab, "CyberSecurity attack prediction: a deep learning approach," in Proceedings of the 13th International Conference on Security of Information and Networks, pp. 1-6, NJ, USA, July 2020.

[89] M. Boujelben, O. Cheikhrouhou, H. Youssef, and M. Abid, “A pairing identity based key management protocol for heterogeneous wireless sensor networks," in Proceedings of the 2009 International Conference on Network and Service Security, pp. 1-5, IEEE, Paris, France, June 2009.

[90] I. Jemal, O. Cheikhrouhou, H. Hamam, and A. Mahfoudhi, "Sql injection attack detection and prevention techniques using machine learning," International Journal of Applied Engineering Research, vol. 15, pp. 569-580, 2020a.

[91] I. Jemal, M. A. Haddar, O. Cheikhrouhou, and A. Mahfoudhi, "ASCII embedding: an efficient deep learning method for web attacks detection," Pattern Recognition and Artificial Intelligence, vol. 1322, pp. 286-297, 2021 a.

[92] I. Jemal, M. A. Haddar, O. Cheikhrouhou, and A. Mahfoudhi, "Malicious http request detection using code-level convolutional neural network," Lecture Notes in Computer Science, Springer International Publishing, in Proceedings of the Risks and Security of Internet and Systems: 15th International Conference, CRiSIS 2020, pp. 317-324, November 2020.

[93] I. Jemal, M. A. Haddar, O. Cheikhrouhou, and A. Mahfoudhi, "M-CNN: a new hybrid deep learning model for web security," in Proceedings of the 2020 IEEE/ACS 17th International Conference on Computer Systems and Applications (AICCSA), pp. 1-7, IEEE, Abu Dhabi, UAE, February 2020b. 